Etnográfica

Revista do Centro em Rede de Investigação em

Antropologia

vol. $22(3) \mid 2018$

Vol. $22(3)$

\title{
Enfrentando al neoliberalismo en Colombia: arte y colaboración en un hospital en ruinas
}

Confronting Neoliberalism in Colombia: art and collaboration in a hospital in ruins

\section{César Ernesto Abadía Barrero y Héctor Camilo Ruiz Sánchez}

\section{(2) OpenEdition}

Journals

Edición electrónica

URL: https://journals.openedition.org/etnografica/6138

DOI: 10.4000/etnografica.6138

ISSN: 2182-2891

\section{Editor}

Centro em Rede de Investigação em Antropologia

\section{Edición impresa}

Fecha de publicación: 1 octubre 2018

Paginación: 575-603

ISSN: 0873-6561

\section{Referencia electrónica}

César Ernesto Abadía Barrero y Héctor Camilo Ruiz Sánchez, «Enfrentando al neoliberalismo en Colombia: arte y colaboración en un hospital en ruinas», Etnográfica [En línea], vol. 22 (3) | 2018 Publicado el 10 octubre 2018, consultado el 20 enero 2022. URL: http://journals.openedition.org/ etnografica/6138; DOI: https://doi.org/10.4000/etnografica.6138

\section{(c) (7) (8)}

Etnográfica is licensed under a Creative Commons Attribution-NonCommercial 4.0 International License. 


\section{Enfrentando al neoliberalismo en Colombia: arte y colaboración en un hospital en ruinas}

\section{César Ernesto Abadía Barrero \\ y Héctor Camilo Ruiz Sánchez}

Este articulo hila la historia del Instituto Materno Infantil (IMI) - parte del emblemático Hospital San Juan de Dios (HSJD) de Colombia - a la de sus trabajadoras y a nuestra participación a través de una etnografía colaborativa nutrida por el arte y el activismo. El IMI es en uno de los hospitales públicos más importantes del país, cerrado en el 2006 como resultado de la implementación de las reformas neoliberales al sistema de salud colombiano. El artículo muestra algunas intersecciones entre arte, activismo y antropología.

PALABRAS-CLAVE: arte, etnografía, investigación-acción, salud.

Confronting Neoliberalism in Colombia: art and collaboration in a hospital in ruins - This article interconnects the history of Instituto Materno Infantil (IMI) - a component of the emblematic Hospital San Juan de Dios (HSJD) of Colombia - with that of its workers and with our participation through a collaborative ethnography filled by art and activism. IMI is one of the most important public hospitals of the country. It was closed down in 2006 as a result of the implementation of neoliberal reforms to the country's health care system. The article shows some intersections between art, activism and anthropology.

KEYWORDS: art, ethnography, action-research, health.

ABADÍA BARRERO, César Ernesto (cesar.abadia@uconn.edu) - University of Connecticut, USA.

RUIZ SÁNCHEZ, Héctor Camilo (hcr7@pitt.edu) - University of Pittsburgh, USA. 


\section{INTRODUCCIÓN Y NOTA PARA EL LECTOR}

Lo que aquí presentamos hace parte de una propuesta de investigación-acción de larga duración que inició en 2005 cuando quisimos entender los efectos de la privatización de la salud y el cierre de hospitales públicos en Colombia. ${ }^{1}$ El Instituto Materno Infantil (IMI) es el primer y más importante hospital universitario de maternidad y neonatología del país. Si bien ganó estatus administrativo como instituto independiente, hace parte del complejo hospitalario San Juan de Dios, fundado en el siglo XVI, y es cuna de los avances más importantes en medicina clínica en el país debido a su relación simbiótica con la Facultad de Medicina de la Universidad Nacional de Colombia. Este complejo hospitalario, desde su carácter público y universitario, ha acompañado la historia del país, desde la colonia hasta el presente, pasando por el periodo independentista y la consolidación de la República. En medio del desarrollo de Bogotá, la carrera décima separó el IMI del resto de edificios del complejo hospitalario, pero un túnel lo mantendría conectado para permitir que pacientes, trabajadores y personal de salud profesional o en entrenamiento transitaran de un lugar a otro. Debido a las reformas neoliberales en salud que se promulgaron inicialmente con la Ley 100 de 1993, los hospitales fueron evaluados como ineficientes y costosos para finalmente ser declarados insostenibles. El Hospital San Juan de Dios (HSJD) fue cerrado en el año 2000 y el IMI en 2006.

En este artículo reportamos nuestro seguimiento y acompañamiento a un grupo de trabajadoras del hospital y rescatamos varios procesos que oscilaron entre el activismo y la academia. ${ }^{2}$ De esta forma, presentamos este artículo como un aporte desde una antropología que asume el reto político de sus actos (Oliveira 2004; Hall 2006) y que, en este caso, busca crear alternativas mediáticas para transmitir la historia y el análisis crítico de uno de los hospitales más importantes de Colombia, que sucumbió ante las políticas neoliberales en salud. En esta historia se evidencia el rápido proceso de deterioro del hospital, así como la lucha de un puñado de sus trabajadoras por mantener el hospital

I Para este artículo ambos autores aportaron partes iguales de trabajo, ideas y tiempo en conceptualización, trabajo de campo, análisis y escritura. Por lo tanto, ambos se reconocen como primeros autores. El artículo y los recorridos aquí descritos no hubieran sido posibles sin el apoyo y el trabajo de las trabajadoras de La Carpa IMI, del Grupo de Antropología Médica Crítica de la Universidad Nacional de Colombia, y del colectivo IMIenEspera. El colectivo IMIenEspera estuvo conformado por los artistas Juana Méndez, Nicolás Escalante Ruiz, Arturo Anaya y Javier Gamboa; la gestora cultural Elisa Mendiola López; y los antropólogos Ingrid Morris y Héctor Camilo Ruiz.

2 Es importante anotar que de ahora en adelante nos referiremos a los y las trabajadoras del hospital en femenino, ya que la mayoría de las trabajadoras son mujeres. En otro ejercicio de investigación-acción, uno de los trabajadores hombres propuso el uso femenino para representarles, no solo por la mayoría numérica sino porque el sentido de la maternidad es femenino. 
abierto, por defender sus derechos laborales, y por preservar un sentido público al derecho a la atención en salud en el país.

Este artículo está acompañado de varios vínculos a material audiovisual disponibles en Internet. Por lo tanto, una lectura de su versión digital puede resultarle al lector más interesante si este desea acceder a material adicional que se ha realizado en los últimos años y que concierne al IMI y a acciones específicas que se describen en este artículo. Sin embargo, el texto impreso cuenta con suficiente material fotográfico para ser comprendido y disfrutado. La versión digital y física son exactamente las mismas, pero los vínculos ofrecen una inmersión más rica, auditiva y visual, a lo aquí presentado.

El artículo cuenta la historia de resistencia de un grupo de trabajadoras que se auto-denominaron "La Carpa" y que decidieron hacerle frente a la privatización y cierre del hospital. También relata la forma como diferentes acciones artísticas se integran a su lucha y como éstas ayudan a comprender la historia. Brindaremos inicialmente un breve contexto sobre la privatización de la salud en el país, sobre el hospital y sobre cómo aparecemos nosotros en la escena del mismo.

En lo concerniente a la intersección entre arte y activismo, nos detendremos en dos propuestas. La primera desarrollada por las y los trabajadores, quienes crearon grafitis en paredes, telas y papeles, tanto al interior como al exterior del hospital. La segunda obedece al proceso de construcción y puesta en escena de tres visitas guiadas en el IMI hechas en el 2011 por un colectivo artístico del cuál participamos en colaboración con las trabajadoras de La Carpa. Terminaremos con algunas reflexiones sobre los significados de estas expresiones artísticas para una antropología que asume la política y el activismo como componentes importantes de su ejercicio.

\section{LA PRIVATIZACIÓN DE LA SALUD Y LOS HOSPITALES PÚBLICOS}

Al igual que en otros países de América Latina, los hospitales públicos en Colombia han seguido las transformaciones políticas y los vaivenes sociales y desarrollos científicos del país. El HSJD en Bogotá y su ala de maternidad, el IMI, surgieron de la mano de la colonia y acompañaron al país en sus luchas independentistas y en la consolidación de la República (Bochetti, Arteaga y Palacios 2005; Restrepo Zea 2011). Estos hospitales finalmente se consolidarían como hospitales modernos de la mano de la Universidad Nacional de Colombia, la cual fue su regente académica años después desde la fundación de la Facultad de Medicina en el siglo XIX (Restrepo Zea 2011). A lo largo de esta historia, estos hospitales han mantenido complejas relaciones administrativas con el Estado y han sido objeto de múltiples disputas sobre su origen y "dueño", incluyendo a la Beneficencia de Cundinamarca, al Ministerio de Salud, la misma Universidad Nacional e inclusive, por varios años, una 
fundación privada sin ánimo de lucro. Gracias a la lucha de las trabajadoras del HSJD, los decretos que sustentaban jurídicamente esta fundación fueron derogados por el Consejo de Estado y los hospitales volvieron a tener un carácter público (Góngora et al. 2013).

En 1975 los hospitales fueron integrados al Sistema Nacional de Salud y funcionaron como centros principales de referencia para pacientes con necesidades de cuidado de altos niveles de complejidad. A pesar que la financiación estatal siempre fue deficiente y la crisis económica era una constante en la vida de los hospitales, estos eran considerados los centros principales del conocimiento médico en el país y los egresados de medicina de la Universidad Nacional tenían gran prestigio debido a que sus prácticas se desarrollaban en el HSJD y el IMI. A pesar del deseo de avanzar hacia un sistema público e integrado, el Sistema Nacional de Salud era fragmentado y la calidad de la atención variaba mucho dependiendo del acceso a redes de servicios (Hernández Alvarez y Obregón Torres 2002). El cambio principal ocurriría de la mano de las reformas neoliberales. En 1993, con la Ley 100, Colombia estableció una de las reformas privatizadoras más fuertes a nivel mundial al obligar a toda la población a afiliarse mediante pagos o subsidios a un sistema basado en pólizas individuales de salud administradas por agentes intermediarios de mercado conocidos como aseguradoras (Yepes et al. 2010). Los hospitales públicos, como el HSJD y el IMI, fueron obligados a transformar sus lógicas culturales hacia la administración de servicios, la facturación y las cuentas de cobro. Con el tiempo, el sistema fue denunciado por aumentar las inequidades, por sus altos márgenes de corrupción, ya que las aseguradoras secuestraron la mayoría de los recursos del sistema, se negaban a pagar sus cuentas e, inclusive, malversaron los recursos destinados para la salud de la población. En últimas, pacientes y hospitales quedarían a merced del gran negocio de las aseguradoras en salud.

\section{IMI: PERSONAS, OBJETOS, FOTOGRAFÍAS, NARRATIVAS, EMOCIONES}

En medio de este proceso de la reforma neoliberal fue que llegamos al IMI, cuya planta de profesores y trabajadores seguía siendo considerada ejemplar. El IMI ganó prestigio nacional e internacional por tratar los casos más complejos de ginecología y neonatología del país, y por servir a los sectores más pobres de su población. Debido a la crisis financiera constante y a su característica como centro de la medicina en el país, el IMI funcionaba bajo un ritmo paradójico de limpieza, excelencia médica y humanismo, que contrastaba con equipos desactualizados, viejas sábanas, paredes agrietadas, falta de pintura, ascensores destartalados, e incluso techos cayéndose a pedazos. Sin embargo, en la dinámica cotidiana y mientras estuvo funcionando, el total compromiso de las y los trabajadores del hospital protegió a los pacientes de las fallas institucionales y de las múltiples dificultades económicas que se vivían en el día a día. 


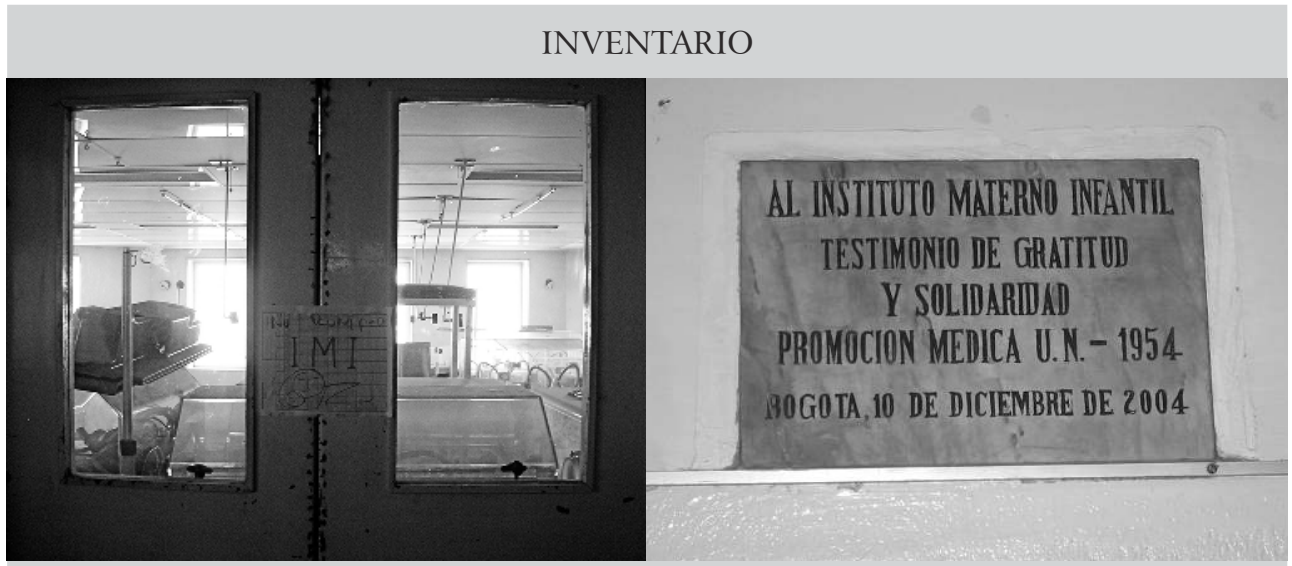

Figuras 1 y 2 - Sellamiento para la protección de incubadoras hecho por trabajadoras de La Carpa; placa de agradecimiento y solidaridad de la promoción de médicos de 1954. Fotografías: César Ernesto Abadía Barrero, 2006.
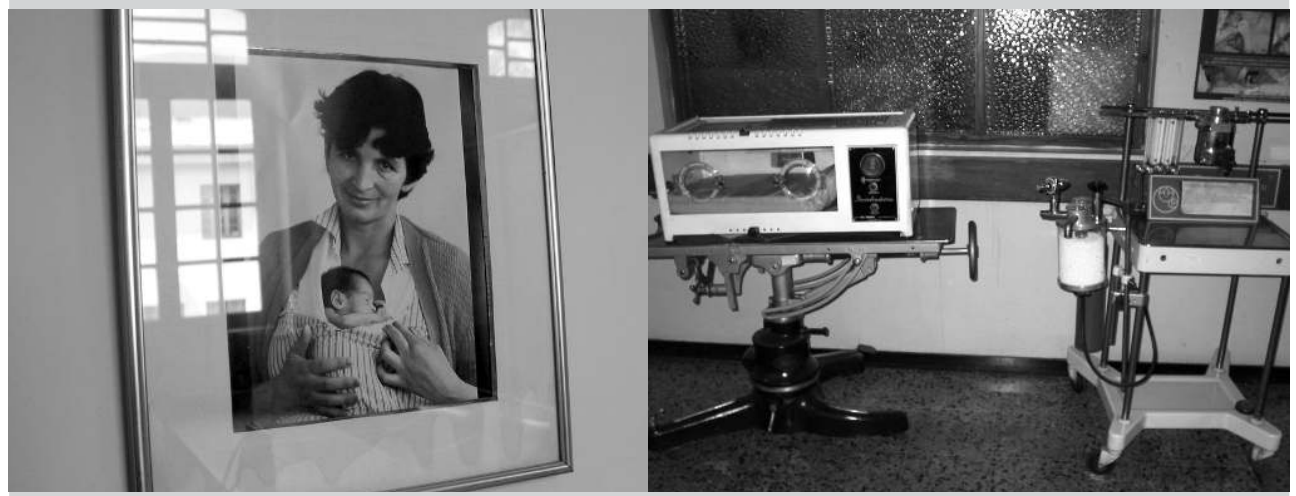

Figuras 3 y 4 - Retrato de madre cargando a su bebe al estilo canguro; parafernalia médica parte del museo IMI.

Fotografías: César Ernesto Abadía Barrero, 2006.

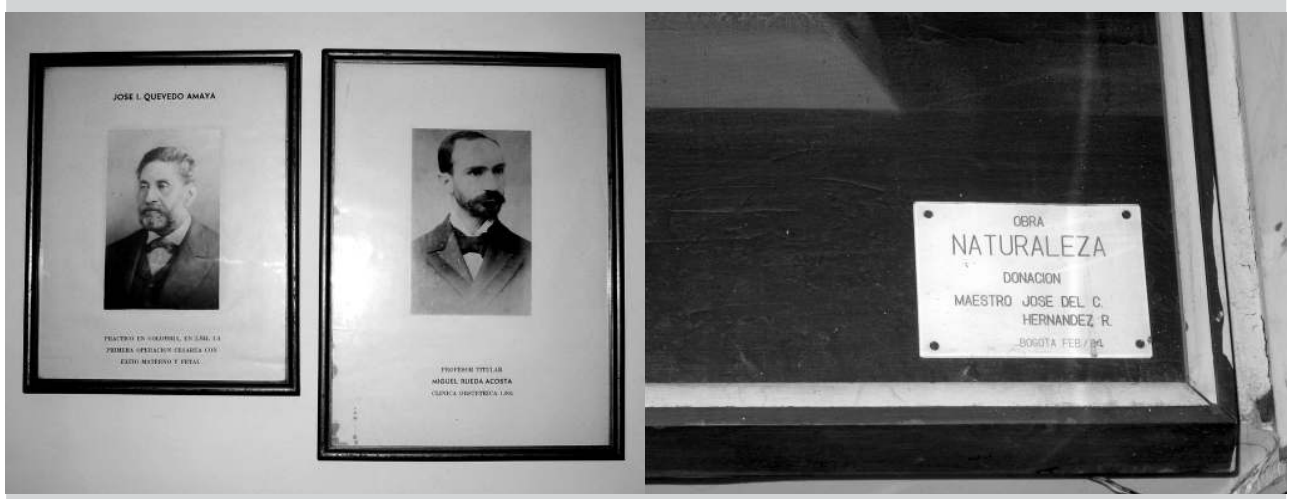

Figuras 5 y 6 - Fotos de personajes importantes en la historia del IMI; placa adjunta a un cuadro donado al IMI.

Fotografías: César Ernesto Abadía Barrero, 2006. 
En el año 2005, autoridades gubernamentales anunciaron que el IMI, siguiendo la historia de otros hospitales públicos, iba a ser cerrado, y que los contratos laborales de sus trabajadoras iban a ser liquidados. Directores y jefes de servicio tuvieron que entregar inventarios actualizados de los bienes del hospital, además de sus llaves. La enfermera jefe Gloria, encargada de los programas de investigación y educación, fue una de las trabajadoras que tuvo que cumplir con esta exigencia. Junto con Marcela, la secretaria de la jefe Gloria, César ayudó a hacer inventarios, lo cual implicó ir a cada salón de clase y anotar los números de registro de cada una de las sillas, escritorios, tableros y demás objetos, sin importar lo viejos o rotos que estuvieran.

Estos inventarios fueron tal vez los primeros recorridos de los que hicimos parte. La tradicional observación participante del trabajo de campo antropológico era cuestionada por la necesidad de actuar y más que la aprobación que había realizado el comité de ética del hospital a nuestra investigación, serían nuestras acciones las que terminarían signando la evaluación ética de nuestro accionar investigativo (Bourgois 1990; Oliveira 2004; Fluehr-Lobban 2008). Desde esa época, transitar por el hospital representa una sensación extraña y paradójica; espacios vacíos entran en diálogo con infinidad de recuerdos, redefiniendo y haciendo aún más difícil de comprender la sensación de ausencia, frío y desolación que transmiten a primera vista. César recuerda como, frente a pinturas y fotos de prominentes figuras de la historia del hospital, el tono del recorrido cambió de una diligencia burocrática a un viaje histórico sobre el legado del hospital. Inevitablemente, los relatos sobre el hospital se convirtieron en relatos sobre las vidas de sus trabajadoras, sobre sus triunfos y sus temores, para en algún momento reparar sobre el deterioro de la salud y las políticas públicas del país. En estos recorridos, que se convertirían en habituales, las y los trabajadores se preguntaban: “¿Dónde van a recibir atención los pacientes más pobres de la ciudad con la calidad y calidez que caracterizaban el IMI?"

En el 2006, ya había muy pocos pacientes. El aspecto inmaculado de los lugares vacíos empezó a ser reemplazado por polvo. Las trabajadoras empezaron a deambular sin rumbo fijo por el hospital, acompañadas de sus preocupaciones. Algunas salas de consulta, hospitalización y administración se convirtieron en lugares de reunión, y las ollas de café facilitaron la creación de nodos donde se tejían conversaciones, mantas y atuendos, mientras se dejaban pasar las horas a la espera de algún milagro que salvara el hospital o de un desenlace definitivo.

La tensión y la incertidumbre escalaron rápida y profundamente. Finalmente, el último paciente del hospital fue transferido, y progresivamente, la falta de salarios y falsas promesas de nuevos trabajos llevaron a la mayoría de las trabajadoras a renunciar a sus cargos y perder sus acreencias laborales. Aquellas que se rehusaron a firmar la renuncia, principalmente quienes estaban próximas a cumplir los requisitos de pensión después de 20 años de trabajo, 
gracias a las conquistas sindicales, encontraron sus nombres el 28 de diciembre de 2006 en un edicto: una lista pública que anunciaba su desvinculación con la institución. Sin embargo, en un acuerdo con el ministerio público, lograron que se les garantizara su presencia en una parte del edificio del hospital, mientras que el "proceso de liquidación" seguía su curso, y su situación laboral se esclarecía.

Este grupo de trabajadoras, ilegalmente despedidas y no liquidadas, se convertiría en un colectivo político en defensa de sus derechos laborales y del hospital, como institución insignia de la salud en el país, monumento histórico y bien patrimonial. Quienes permanecieron conformando este grupo político eran antiguas trabajadoras de distintas áreas clínicas, administrativas y de servicios generales, con edades entre los 35 y 70 años. Si bien algunos hombres conformaban este grupo, su gran mayoría eran mujeres y fue el mismo colectivo, en una de las múltiples actividades y sesiones de trabajo que acompañamos, quien asumió una identidad colectiva femenina para señalar que gran parte de las violaciones a los derechos al trabajo y a una vida digna ocurría en mujeres. Igualmente es destacable que, en este proceso, algunas lograron conseguir otros trabajos, pero la gran mayoría no y la situación económica se precarizó a tal punto que muchas perdieron sus viviendas, y en muchos casos sus familias se desintegraron, en gran parte debido a la difícil situación económica y emocional que les tocó vivir.

Aquí es importante anotar que, en el año 2006, dos de los cinco pisos del hospital fueron arrendados por la agente liquidadora al Hospital La Victoria (HLV). Este hecho generó fricciones que variaran de intensidad a través de los años; sin embargo, el hecho de asfixiar a un hospital nivel cuatro (el máximo posible en Colombia) para dar paso a uno de segundo nivel en el mismo edificio fue un acto que creó profundo malestar entre las trabajadoras del IMI.

El hospital sin pacientes se sentía frio y abandonado. Algunas áreas que eran muy activas en el pasado se habían convertido en lugares espectrales; y las zonas ya deterioradas parecían derrumbarse aún más cada vez que les dábamos la espalda. Las sillas, las camillas, las mesas, los carros de medicamentos, las alacenas y hasta los lavamanos iban perdiendo sus partes; así, poco a poco, todo iba apilándose en esquinas y bodegas improvisadas, o "aparecían" expuestos a la intemperie en el parqueadero del hospital. Las opacas incubadoras, que en alguna época mantenían con vida a varios bebés, ahora solo representaban objetos de inventario.

Es importante anotar que el complejo hospitalario había sido declarado patrimonio cultural y monumento nacional mediante la Ley 735 de 2002, debido a otra acción de las trabajadoras del HSJD; por lo tanto, mantener el registro de los inventarios se convirtió en una parte importante del trabajo de protección de los hospitales. En varios momentos, las trabajadoras de $\mathrm{La}$ Carpa nos solicitaron copias de las fotografías que habíamos tomado en esos 
recorridos para que apoyaran al registro y las denuncias que estaban efectuando ante la pérdida de los bienes patrimoniales. Para las trabajadoras, el edificio se estaba deteriorando, a la par que su contenido se estaba vaciando, y los dos componentes, edificio y objetos, eran parte de los bienes materiales que habían creado la historia de la ginecología y neonatología en el país.

Varias de las fotografías iniciales que acompañaron los ejercicios del inventario se convertirían, entonces, en evidencia de "deterioro patrimonial" que, años más tarde, traería una nueva victoria a las trabajadoras cuando una demanda prosperó y la liquidadora que tanto daño infringió a ellas y al hospital fue obligada a renunciar. La fotografía, en este caso, sería arte y objeto de denuncia a la vez.

\section{ACOMPAÑAR: UN EJERCICIO EMOCIONAL E INTELECTUAL}

Para el año 2008 la atmósfera era tensa y algo depresiva; el llanto se apoderó más frecuentemente de las trabajadoras. De esta manera empezamos a recolectar relatos más personalizados sobre cómo el "proceso de liquidación" estaba afectando a cada una de ellas, cómo lo estaban enfrentando, e intentamos entender como las vidas de estas mujeres estaban hiladas orgánicamente a la vida misma del hospital.

Invitamos a las trabajadoras a una presentación sobre el IMI en el Centro de Estudios Sociales de la Universidad Nacional, incluyendo a la enfermera jefe Gloria y a Marisol, lideresa de las trabajadoras. Durante 20 minutos intensos de fotografías y extractos de entrevistas leídos en voz alta por compañeras del grupo de investigación mostramos rasgos del proceso de destrucción psico-emocional por el que estaban pasando. Queríamos hacer un doble llamado para hacer reflexiones más profundas sobre la relación entre violencia neoliberal y el Estado colombiano, y extender nuestra solidaridad con las trabajadoras.

Terminamos la presentación con la propuesta de pensar este proceso como un tipo de tortura liderada y auspiciada por el neoliberalismo, y materializada en el proceso de liquidación. Los académicos invitados al evento comenzaron a discutir si tortura era un concepto adecuado para describir la situación de las trabajadoras. Después de algunas intervenciones, Marisol tomó la palabra. Cuando esta férrea lideresa comenzó a hablar y reflexionar sobre los resultados de la investigación, fue sobrecogida por una marea emocional y dijo que no sabía muy bien como los investigadores entendíamos lo que era tortura, pero que ella sentía que lo que había pasado y por lo que estaba pasando, era efectivamente eso, tortura. ${ }^{3}$

3 Una descripción más a fondo de este proceso se puede encontrar en el artículo de Abadía Barrero et al. (2011). Para un análisis de la compenetración entre trabajadores y edificación y el significado de la destrucción de los mismos, ver Abadía-Barrero (2015). 
Algún tiempo después, Marisol compartió con nosotros lo importante que había sido nuestro proceso investigativo con ellas. También nos dijo como la idea de tortura le había permitido entender el proceso por el que estaban pasando sus compañeras, y que lograr entenderlo generaba de alguna manera alivio. Resaltó además que escuchar nuestros relatos sobre ellas resultaba en un reconocimiento a la forma como entendían su historia y no era, como muchas veces habían - y habíamos - escuchado, que estaban locas, que todo lo que decían era una invención, que nada de lo que ellas contaban era real.

En este caso, el registro fotográfico hilado a las narrativas logró configurar un tipo de etnografía viva, al transmitir un sentido colectivo que, además de emociones, lograba politizar la lucha con una categoría en donde se podía identificar un actor o proceso externo como causante de la destrucción del hospital, en este caso la liquidadora y el proceso de liquidación.

\section{GRAFITI: TRABAJO Y POLÍTICAS NEOLIBERALES}

"el grafiti se alimenta de momentos históricos y sus anónimos ejecutores son los agentes que, con ciertas características personales o grupales, materializan por medio de escrituras o representaciones ocasionales, anhelos o frustraciones de una colectividad, o bien exaltan formas que regresan o cuestionan a sus territorios sociales" (Silva Téllez 2013: 23).

Las trabajadoras del IMI, siguiendo una larga tradición de protesta que siempre caracterizó al hospital, han escrito y rayado sobre muros, ventanas y muebles; han pegado carteles usualmente al interior del hospital y han usado como lienzos grandes telas que luego cuelgan en las fachadas del hospital. Las técnicas y materiales usados para pintar y rayar son variados, incluyendo pintura, tizón, sprays o lápiz labial en ausencia de cualquier otro material y ante la necesidad urgente de expresarse. Con estos escritos, que de ahora en adelante llamaremos grafitis, las trabajadoras resaltan que lo importante no es el medio o material utilizado, sino dejar constancia, criticar e incomodar. El grafiti aquí es, entonces, una estrategia de lucha política en la que tiempo, espacio y mensaje convergen en un acto estético-político.

Los grafitis del IMI comparten un deseo de denuncia y una autoría colectiva y anónima. El acto de denunciar, "generar conciencia" o culpar también contiene un sentimiento de ira, impotencia, malestar, y el deseo de restablecer lo que se considera digno. Por lo tanto, las diferentes manifestaciones gráficas del IMI se convierten en un archivo y un conjunto de elementos de queja, en el sentido jurídico de la palabra, en el que la queja o reclamo se hace para dejar constancia de una injusticia.

Postulamos que los grafitis deben ser leídos como parte de una autoría colectiva anónima, porque sabemos que las diferentes obras gráficas son de La Carpa, 


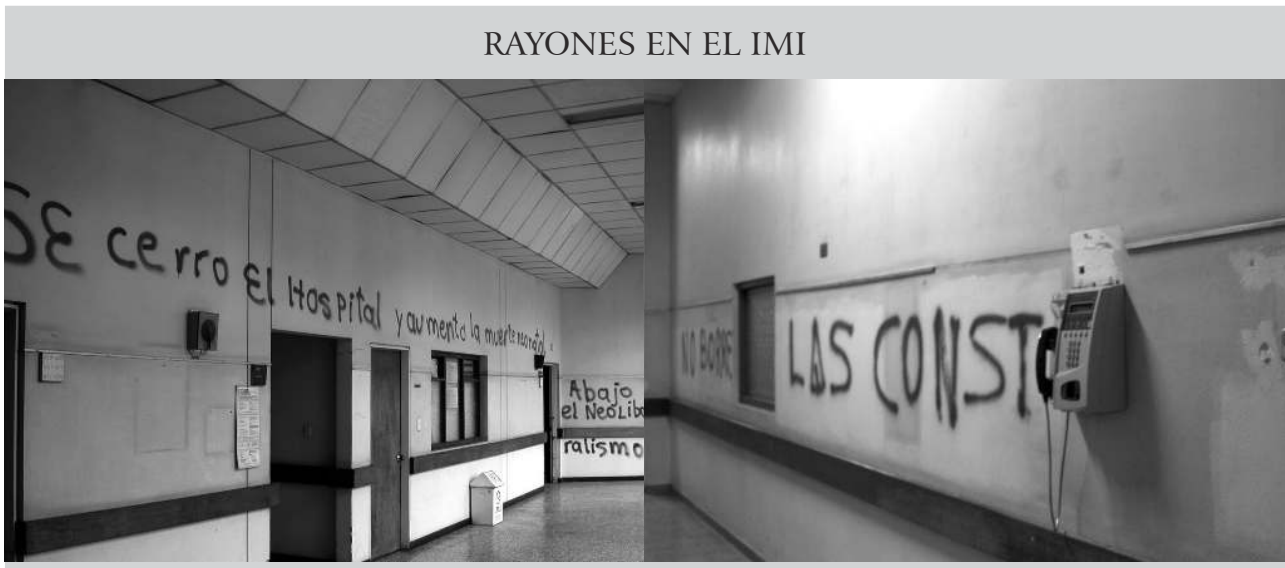

Figuras 7 y 8 - "Se cerro el hospital y aumento la mortalidad materna”, "Abajo el neoliberalismo", pasillo IMI; "no borre la const”, pasillo IMI.

Fotografías: Héctor Camilo Ruiz Sánchez, 2009-2011. Grafitis: La Carpa IMI.

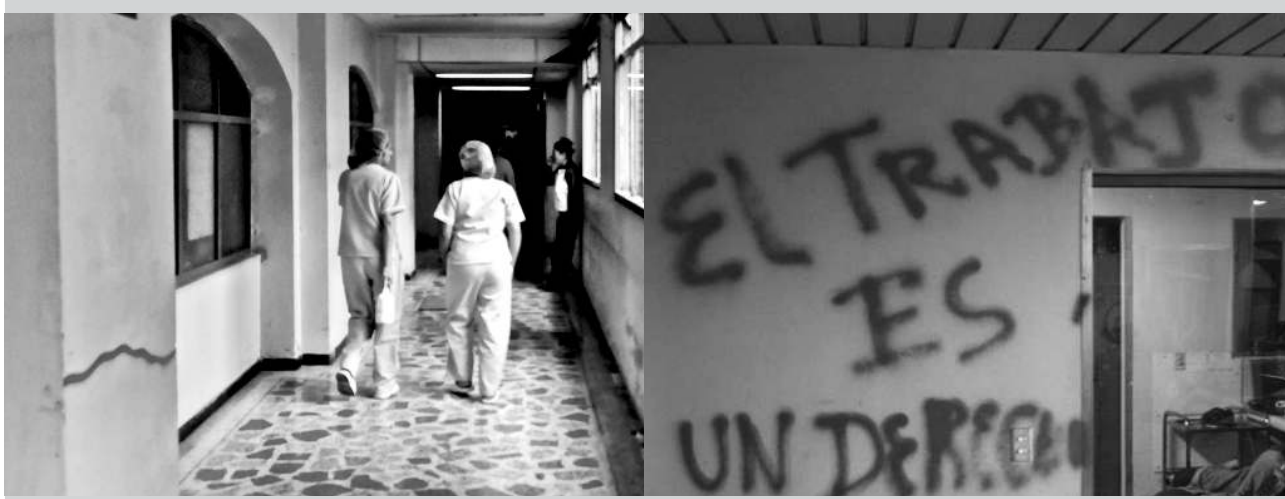

Figuras 9 y 10 - Rayón tipo electrocardiograma (muro izquierdo), pasillo IMI; "El trabajo es un derecho", admisiones.

Fotografías: Héctor Camilo Ruiz Sánchez, 2009-2011. Grafitis: La Carpa IMI.

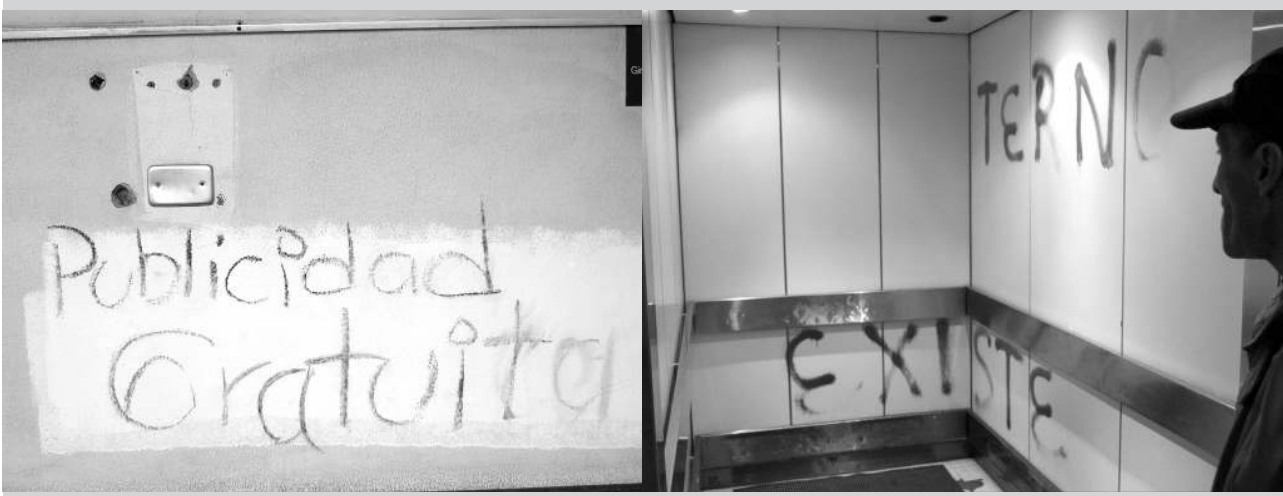

Figuras 11 y 12 - "Publicidad Gratuita", pasillo IMI; "terno... existe", ascensor IMI. Fotografías: Héctor Camilo Ruiz Sánchez, 2009-2011.

Grafitis: La Carpa IMI. 
pero al mismo tiempo sabemos que La Carpa representa a cientos de trabajadores. De esta manera, la autoría individual se desvanece y se convierte, como Michel Foucault lo llamaría, en un "discurso" (Foucault 1984). A diferencia de propuestas artísticas hegemónicas, los grafitis de La Carpa enseñan que el arte como estrategia de lucha prioriza el sentido político del mensaje por encima del material o la técnica y acuña una autoría colectiva y anónima por encima de los deseos de reconocimiento individual.

Mientras que algunas de las intervenciones son mensajes claros y contundentes, otras parecen simplemente rayones hechos rápidamente. Algunos son hechos con paciencia, su lugar ha sido pensado de antemano, y usualmente incluyen oraciones muy elaboradas, mientras que otros aparecen como garabatos hechos espontáneamente, a gran velocidad, y su significado puede tener varias interpretaciones - como el rayón que aparece en la figura 9 que nos recuerda señales de un electrocardiograma a punto de mostrar inactividad cardiaca, como si hubieran querido indicar que el paciente está a punto de morir (imagen con gran carga simbólica en su contexto, y donde la lectura de simple rayón se desdibuja y se transforma en una obra gráfica que se acerca al arte conceptual).

Armando Silva nos ayuda a entender al grafiti, el cual en una primera aproximación puede ser entendido como escritura que pervierte el espacio físico e ideológico y que se inserta en una red de significados cobrando sentido a nivel vecinal (Silva Téllez 2013: 18-19). Este es un punto-clave para entender los grafitis del IMI, ya que es a través del sentido de vecindad, sinónimo de cercanía y empatía con las causas de lucha y resistencia de las trabajadoras del IMI, que uno logra entender a mayor profundidad su significado. La conexión semiótica con los grafitis, entonces, se da a cabalidad cuando el espectador logra conectarse con el drama que allí se vive y éste empatiza ya sea con las causas de resistencia o con las de desalojo. Sin importar la sensación que estos generen, lograr entender los grafitis parte de la cercanía con la historia del IMI, y con el grado de vecindad que el lector tenga con éste.

Pero el público al cual fueron dirigidos estos mensajes claramente no fuimos nosotros, sino los directores del Hospital La Victoria (HLV) y el personal de la agente liquidadora que insistían constantemente en dar una imagen de normalidad al interior de la parte subarrendada del hospital. Recordemos que el hospital, en estos momentos, estaba fraccionado en dos mitades, una que simbolizaba la resistencia de las trabajadoras de La Carpa y una parte subarrendada, en donde el HLV ofrecía atención en ginecología y neonatología de segundo nivel. Así, en el arte grafiti desarrollado por las personas de La Carpa, hay vecinos que muestran empatía y vecinos invasores; y los grafitis tenían la clara intención de transgredir un acuerdo espacial bajo el cual supuestamente deberían coexistir dos instituciones pacíficamente: una (el IMI) en proceso de abandono, cierre y exterminio, y otra (HLV) funcionando en su "nueva sede", 
como fue rebautizado el IMI en la papelería y carteleras con información pedagógica y administrativa.

Bajo esta perspectiva, vemos que el conjunto de grafitis conserva cierta coherencia estética e ideológica como discurso, lo cual da pie para pensarlos y leerlos como archivo. El archivo gráfico de grafitis del IMI es un conjunto de obras que emergen y se plasman sobre el cuerpo del hospital a modo de hitos de memoria y protesta en diferentes momentos de su historia. Estos, al irse acumulando en el espacio y el tiempo, emergen como un conjunto, similar al de los álbumes de fotos de familia (Silva Téllez 1998: 50). Y así como los registros fotográficos familiares almacenados en un libro o una memoria digital están destinados para almacenar los momentos conmemorables de familia y trascender la muerte, los grafitis del IMI, junto con sus registros fotográficos, cumplirían una función similar, pero con una carga afectiva diferente, para recordar la existencia de una suma de injusticias.

Con los mensajes plasmados en los grafitis las trabajadoras han aclarado que ellas no han abandonado el hospital, y al mismo tiempo han incomodado a los arrendatarios (HLV) y los agentes liquidadores. Cada rayón y cada mensaje generan "ruido", "ensucian" y crean malestar. Son medios de denuncia y, como tal, de tensión. El agente liquidador muchas veces ha intentado borrar varios de estos, por ejemplo, repintando alguna pared, para encontrarse con un nuevo rayón sobre la pintura fresca. Pero, aún más, en el acto de rayar hay un acto catártico que mezcla alivio y goce, marcado por la "satisfacción de irrumpir contra [...] el poder político, el económico, el lingüístico" (Silva Téllez 2013: 80). Así, en los grafitis del IMI se ven almacenadas frustraciones y se transmiten emociones de desahogo.

El grafiti ha sido históricamente vetado por su poder de denuncia. Bogotá, en la última década, se ha convertido en meca y referente de dicha manifestación en el continente, tanto así que se han tenido que dar discusiones públicas sobre la naturaleza artística o contaminante de esta forma de expresión. En este contexto, una de las trabajadoras fue abordada un día de 2012 por un grupo de jóvenes que querían hacer un mural/grafiti sobre uno de los muros del parqueadero del IMI que da hacia la carrera décima. El grupo de jóvenes obtuvo permiso de hacerlo por parte de las trabajadoras, siempre y cuando trataran en su grafiti/mural la problemática del hospital.

La trabajadora les explicó a los jóvenes la situación del hospital, para que ellos pudieran plasmarla en el muro, con lo cual se muestra una faceta pedagógica en el que la historia de lucha de las trabajadoras del IMI es transmitida, entendida, plasmada y tal vez sentida por otros. ${ }^{4} \mathrm{El} \mathrm{mural/grafiti,} \mathrm{en} \mathrm{este} \mathrm{caso,}$

4 En un ejercicio similar un colectivo de trabajadoras del HSJD, artistas e investigadores realizaron un Tríptico Audiovisual llamado el "San Juan no Muere, Está de Pie” realizado y dirigido [continua] 


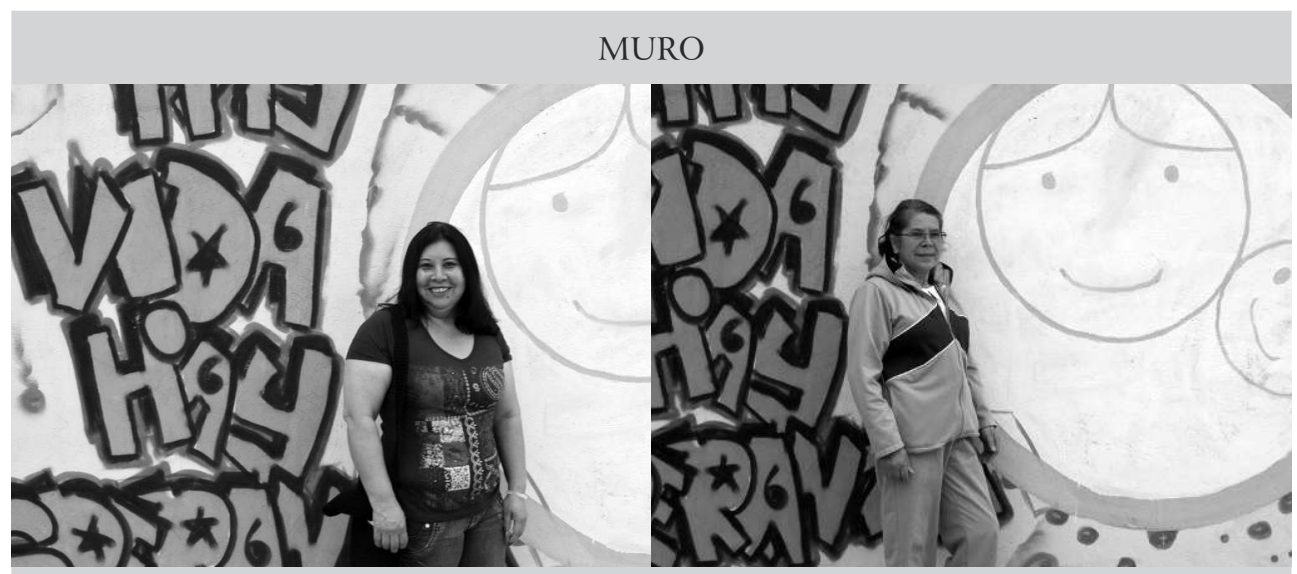

Figuras 13 y 14 - Alejandrina Fiquitiva, trabajadora del IMI; María Cecilia Araque, trabajadora del IMI.

Fotografías: Héctor Camilo Ruiz Sánchez, 2012. Grafiti/mural: Latin Art (Yeyo, Lalo y Erre).

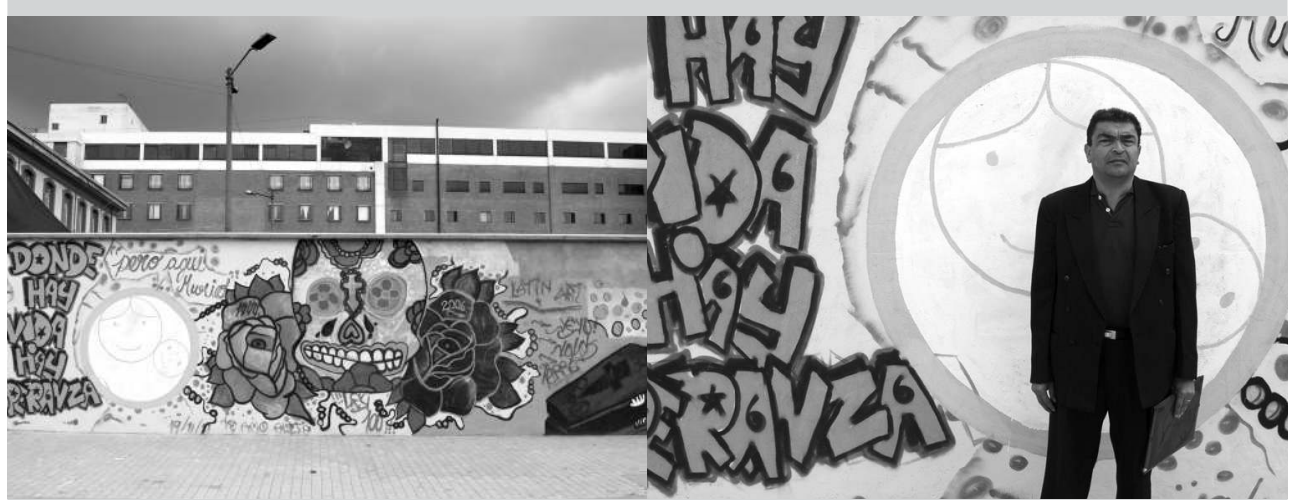

Figuras 15 y 16 - Mural/grafiti "Donde hay vida hay Esperanza"; Miguel Eduardo Tavera Rojas, trabajador del IMI.

Fotografías: Héctor Camilo Ruiz Sánchez, 2012. Grafiti/mural: Latin Art (Yeyo, Lalo y Erre).

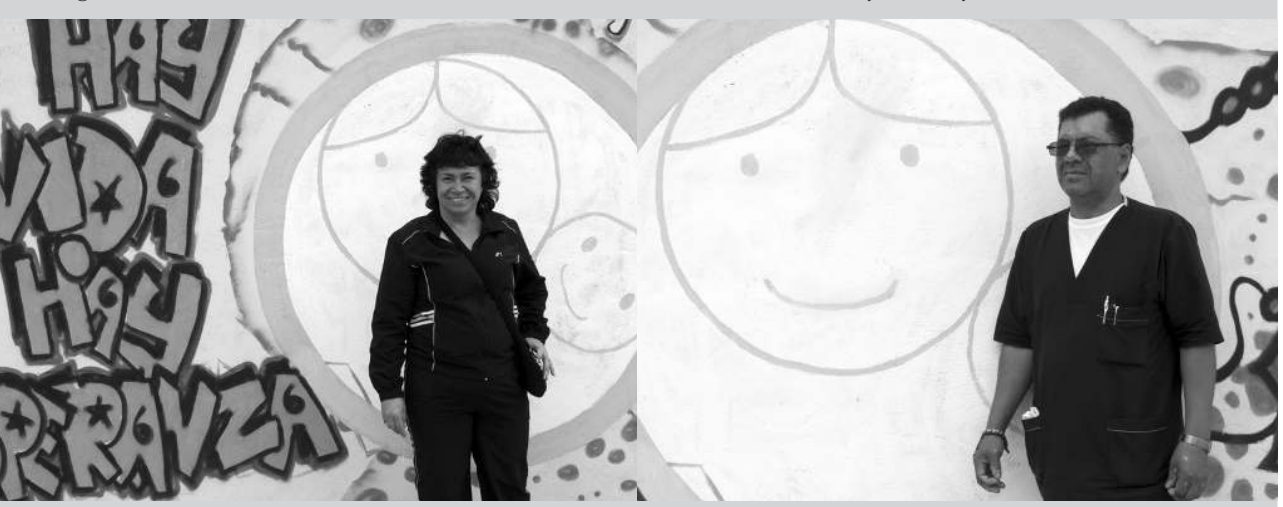

Figuras 17 y 18 - Gilma Carrión, trabajadora IMI; Jesús María Montalvo, trabajador del IMI.

Fotografías: Héctor Camilo Ruiz Sánchez, 2012. Grafiti/mural: Latin Art (Yeyo, Lalo y Erre). 
sirvió para contar y transmitir la historia del IMI a un grupo de jóvenes, para satisfacer los deseos de "rayar" que ellos tenían, y también para proyectar una imagen a un público anónimo que circula por la transitada carrera décima.

Así el archivo de grafitis en el hospital es una forma de registro histórico sobre eventos, momentos, sensaciones y deseos. Vemos como acompañar la elaboración, recomposición y destrucción de grafitis se convirtió en una estrategia etnográfica activista (Hall 2006) para entender y hacer parte de distintos momentos de lucha por las que las trabajadoras del IMI han pasado. La lucha política requiere ser narrada y transmitida. No hay cambio social y muchas veces no hay sentido en resistir si por lo que se lucha no tiene un público que sea capaz de entender, asimilar, sentir y, principalmente, actuar frente a aquello que ha sido evocado. El archivo de grafitis del IMI es en un sentido un archivo moral (Stoler 2002) que cuenta a través de rayones, historias y sentimientos de injusticia y dignidad.

Para nosotros, como etnógrafos, estos grafitis representaron en primera instancia un archivo por el cual es posible hacer un recorrido por la historia de resistencia de La Carpa. Por otro lado, los grafitis nos enseñaron que estas manifestaciones gráficas son una estrategia por la cual las trabajadoras extienden su cuerpo político, temporal y espacialmente. Y fue ese deseo de contribuir con una estrategia similar, pedagógica, política y artística, lo que nos llevó a hacer las visitas guiadas por el hospital.

\section{UNA VISITA GUIADA POR UN HOSPITAL EN RUINAS}

Parafraseado y traduciendo a Sarah Pink (2012), las prácticas de la vida cotidiana no pueden ser vividas o entendidas si estas son aisladas de los actores (practicantes), las representaciones, los eventos, y ocurrencias del lugar al que éstas están ligadas. De esta manera, inspirados por el uso político que las trabajadoras le habían dado al IMI, pensamos que algo similar podía ser realizado en los espacios del hospital para lograr transmitir a un público más amplio lo que allí estaba sucediendo, y tal vez lograr un mayor impacto político. La propuesta era simple en su intención, lograr evocar la magnitud de la catástrofe que había creado el asfixiamiento del IMI y del HSJD en la vida de las trabajadoras, y, más ampliamente, en la salud de la población colombiana.

Empezamos a explorar la idea a través de un taller de pintura sobre camisetas liderado por Juana Méndez, artista plástica, en el cual diseñamos logos del IMI y de La Carpa. En el taller empezamos a discutir las posibilidades de hacer los recorridos. A un grupo de las trabajadoras les gustó la idea, mientras que otras consideraron que la idea requería un gran esfuerzo y que la acción 
no tenía resultados concretos o beneficios a corto plazo para los objetivos de lucha de La Carpa.

Al final solo un grupo de las trabajadoras de La Carpa decidió participar. Continuamos entonces con la idea e invitamos a un grupo interdisciplinario a participar del proyecto y conformamos un colectivo temporal llamado IMIenEspera. De la mano de Marisol y Gustavo, representantes de La Carpa, el grupo de artistas empezó a familiarizarse con historias, anécdotas y espacios del hospital. Acordamos entonces realizar tres recorridos en el que el hospital iba a contar su historia usando voces en vivo y grabadas de sus trabajadoras, imágenes, videos e instalaciones.

El sábado 11 de octubre de 2011 , por la mañana, hicimos el primero de tres recorridos. 25 personas caminaron, vieron, escucharon y sintieron al hospital en 11 lugares representativos. En esta visita el hospital nos mostraba la trayectoria de sus trabajadoras, las luchas icónicas, los atropellos sufridos, y su relación con la ciudad, el país y sus pacientes. ${ }^{5}$

\section{IMIENESPERA}

\section{Ambulancia: la salud esta varada}

El recorrido empezó junto a una vieja pero sólida ambulancia de marca Land Rover que había dejado de funcionar en 2003 porque nunca se autorizó la compra de unos repuestos. Allí mismo, a cada visitante se le dio una manilla de paciente-visitante y una de las trabajadoras empezó a contar la historia del hospital, su importancia, y también las constantes crisis por las que éste había pasado. La crisis actual, ocasionada por la Ley 100 de 1993, como enfáticamente era mencionado, había llevado al hospital a estar sin pacientes, a deberle años de sueldos y prebendas a sus empleados, y a despedirlos con liquidaciones parciales e injustas.

\section{Admisiones}

En lo que durante décadas había sido el espacio de admisiones del hospital, para entonces se había convertido en el nicho de ocupación de La Carpa. Allí siempre había alguien del grupo de resistencia, no importaba la hora o día. Los turnos se iban rotando y usualmente había café de olla. ${ }^{6}$ Aquí los visitantes del recorrido fueron recibidos con café y, guiados por la voz de las trabajadoras,

5 El siguiente vínculo guía al lector a algunos fragmentos de audio que recrean puntos del recorrido, todos en viva voz de las trabajadoras de La Carpa: < https://soundcloud.com/h-camilo-ruiz/sets/imienes pera $>$ (última consulta en Octubre de 2018)

6 El café de olla hace referencia a un café hecho en un recipiente grande y usualmente azucarado con panela, con el objetivo de brindar una bebida caliente y energía a un grupo de personas. El café de olla era un elemento clave en La Carpa, y fueron las mismas trabajadoras quienes decidieron recibir a los visitantes con una taza de café caliente. 

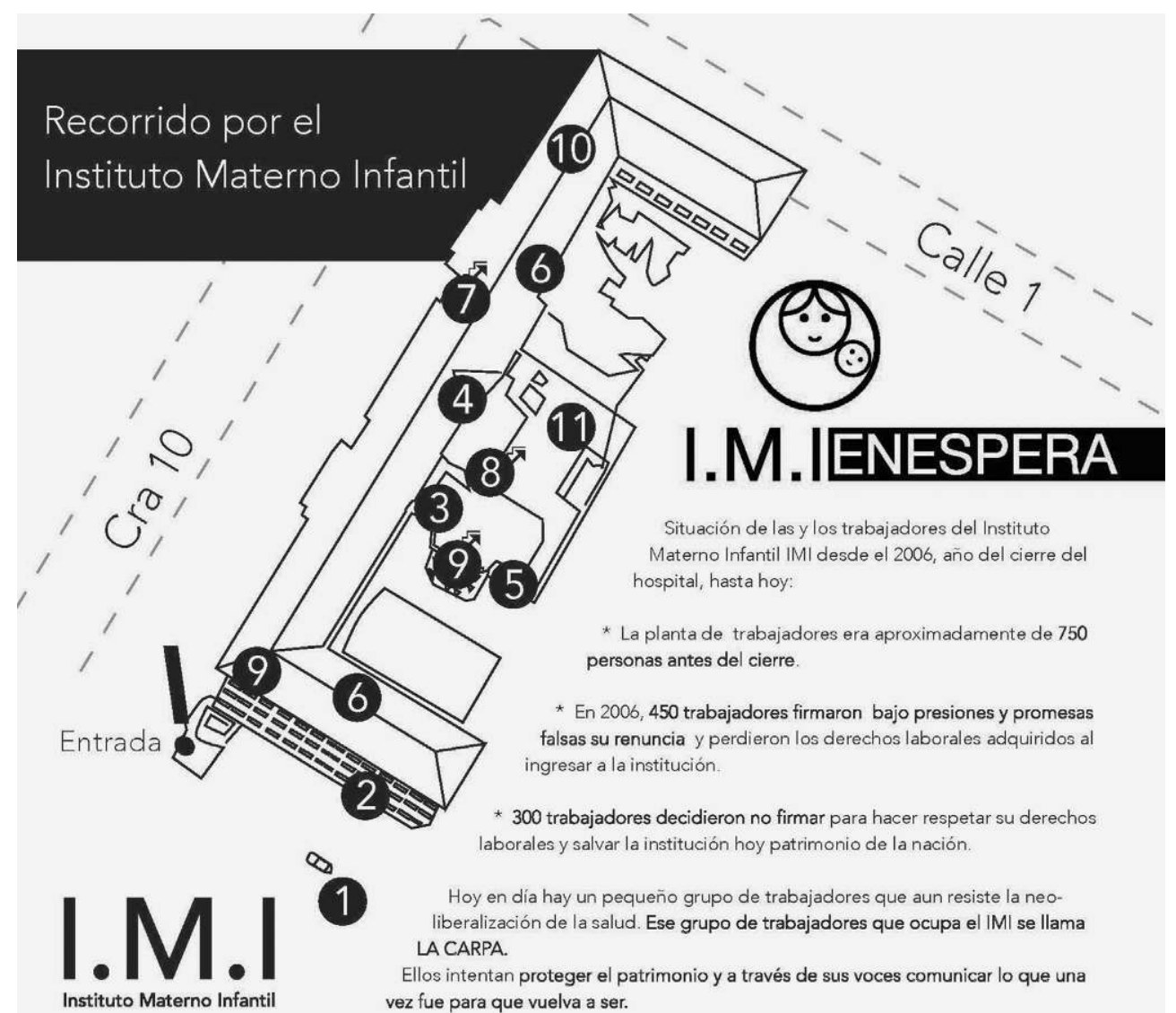

Hoy en día hay un pequeño grupo de trabajadores que aun resiste la neoliberalización de la salud. Ese grupo de trabajadores que ocupa el IMI se llama LA CARPA.

Ellos intentan proteger el patrimonio y a través de sus voces comunicar lo que una vez fue para que vuelva a ser.

\footnotetext{
(1) Ambulancia - Introducción - La salud está varada. Entrega de Manillas.

2 Admisiones - La Carpa y el Instituto Materno Infantil.

(3) Lavandería - Memoria Histórica de un hospital integral y autosuficiente.

(4) Lockers - Ocupación y resistencia por derechos laborales y en contra de la salud Neoliberal.

5 Barricada - Cocina. Intervención - Luz.

6 Programa Canguro-Audio.

(7) Yel San Juan de Dios - Fotografía. Nicolas van Hemelryck. wwwsan-juan-de-dios.com

8 Tomás - Proyección de video: "Bicentenario de la salud en Colombia: Silenciando patrimonios y derechos"

9 El Muro de la discordia- ¿Y el patrimonio qué?.

(10) Hospitalización - Memoria histórica. Cajas de luz

(11) U.C.I - Cajas de luz y testimonio sobre el último paciente del I.M.I
}

Figura 19 - Mapa del IMI (Chapola entregada a todos los visitantes de los recorridos para contextualizar el recorrido en sus puntos clave y su espacio.)

Fotografías: Colectivo IMIenEspera. 
pudieron escuchar a mayor profundidad el estado del proceso legal y laboral por el cual las trabajadoras del IMI estaban atravesando. Allí los visitantes escucharon también sobre la importancia de la ocupación del hospital como un acto digno y justo, y no como una estrategia obstinada de trabajadores sin causa, que buscaban bloquear el hospital, como muchas veces se había retratado en medios masivos de comunicación.

\section{Lavandería}

La siguiente parada fue en la lavandería del hospital, ubicada en un gran salón dividido en dos pabellones, donde funcionaban enormes lavadoras y secadoras. Allí un proyector de diapositivas mostraba sobre el rodillo en desuso de una plancha monumental a pacientes en la década de 1980 tomando el sol en alguno de los patios típicos de la arquitectura francesa del hospital, o jugando fútbol con trabajadores en la cancha de fútbol del HSJD, que a veces servía como helipuerto alternativo. La propuesta allí era dar cuenta de la magnitud de la infraestructura de ambos hospitales, y la dimensión de ciudadela del complejo hospitalario, el cual contaba también con huertas, matadero, amplias zonas verdes, jardín infantil, capilla, entre otros servicios. Al mismo tiempo buscamos transmitir la sensación de catástrofe y abandono que las máquinas y edificaciones encarnaban, al estar ahí destartaladas y en desuso, sabiendo que algún día fueron destinadas para atender y cuidar la vida.

\section{Casilleros}

La siguiente parada se hizo en un cuarto laberíntico, repleto de baldes que intentaban contener inútilmente las innumerables goteras, mientras el óxido iba haciendo lo suyo con los casilleros metálicos. Algunos de estos tenían escritos en corrector los nombres de sus dueños temporales, principalmente estudiantes de la Universidad Nacional y trabajadoras del IMI. Se invitaba a los participantes de los recorridos a acercarse a algunos casilleros para escuchar audios de las trabajadoras relatando el efecto negativo de las violaciones a sus derechos laborales en sus vidas. En otros casilleros se podían ver cajas de luz que proyectaban en acetatos imágenes de resistencia, lucha y ocupación del hospital. Con dicha acción queríamos dar a entender al público que la ruina material del hospital se extendía a sus trabajadoras y familias; y que la resistencia era una acción digna como respuesta a la precarización de la vida.

\section{Barricada-cocina}

En este punto de convergencia entre el edificio y uno de los patios interiores del IMI, se recreó una barricada con elementos en desuso, tales como camillas y sillas, semejando lo que en repetidas ocasiones las trabajadoras de La Carpa habían hecho para contener la entrada de la policía antimotines que ingresaba al hospital en momentos de protesta. Las anécdotas sobre 


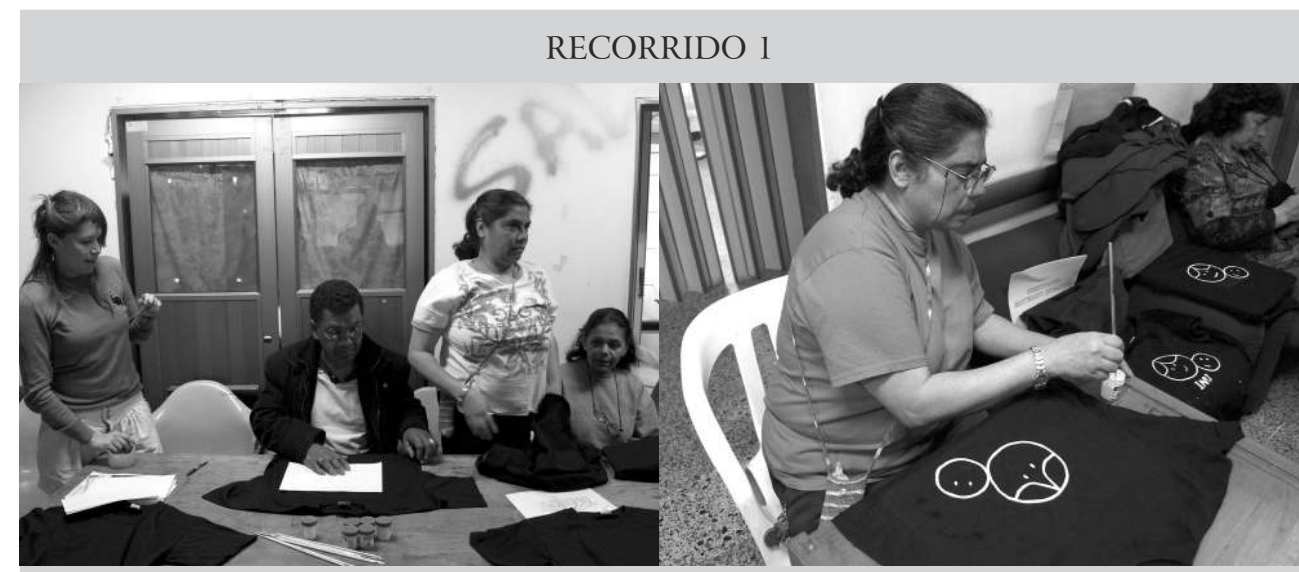

Figuras 20 y 21 - Taller de pintura sobre camisetas.

Fotografías: Colectivo IMIenEspera. 2011.

Instalaciones, talleres y arte gráfico: IMIenEspera y La Carpa.

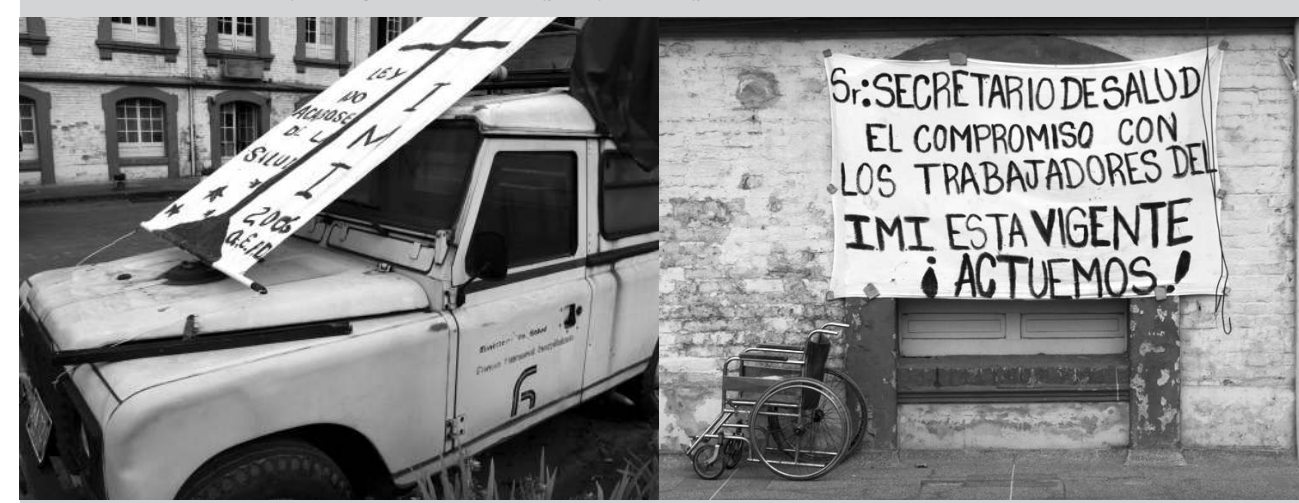

Figuras 22 y 23 - Ambulancia parqueadero IMI; tela con grafiti, fachada sur del IMI. Fotografías: Colectivo IMIenEspera. 2011.

Instalaciones, talleres y arte gráfico: IMIenEspera y La Carpa.

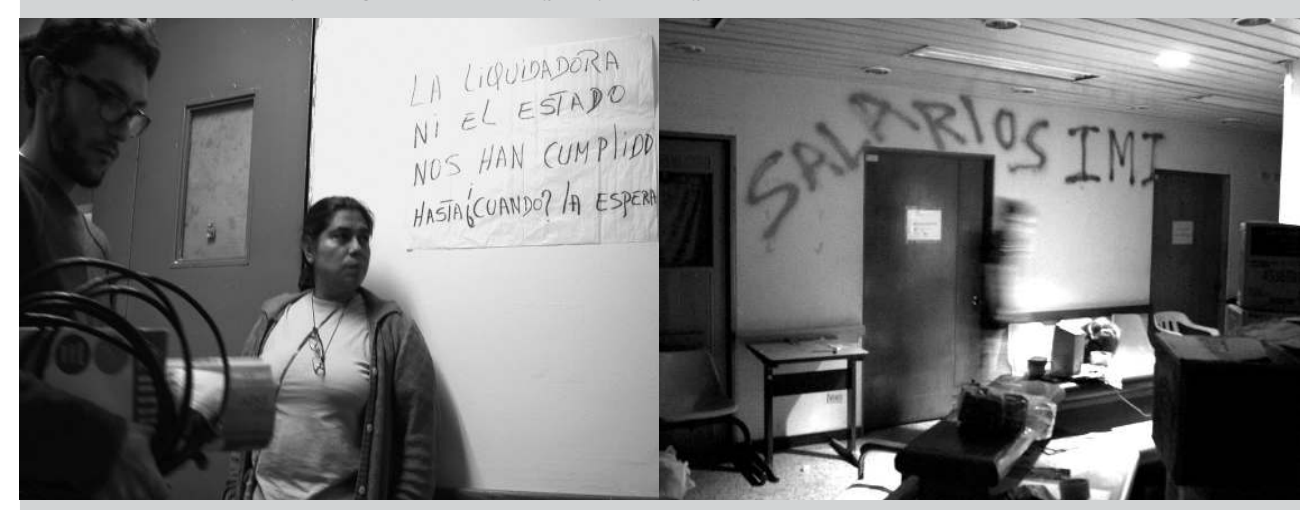

Figuras 24 y 25 - Pasillo IMI; Admisiones IMI.

Fotografías: Colectivo IMIenEspera. 2011.

Instalaciones, talleres y arte gráfico: IMIenEspera y La Carpa. 


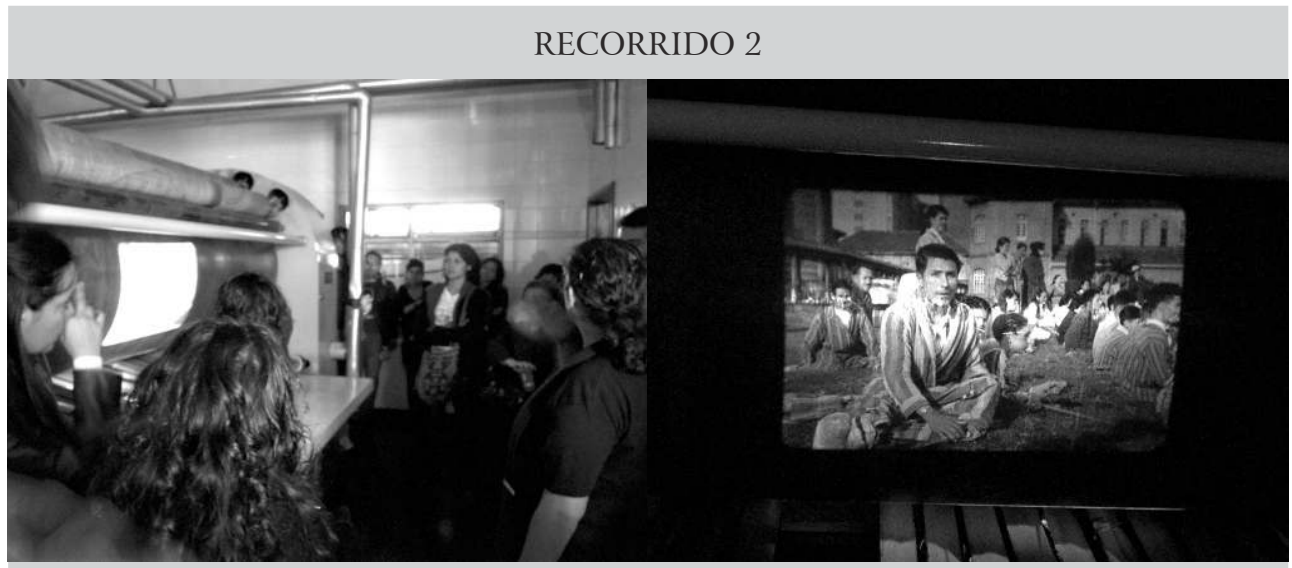

Figuras 26 y 27 - Lavandería IMI; proyección sobre rodillo de secadora en la lavandería IMI.

Fotografías: Colectivo IMIenEspera. 201 1. Instalaciones, talleres y arte gráfico: IMIenEspera y La Carpa.

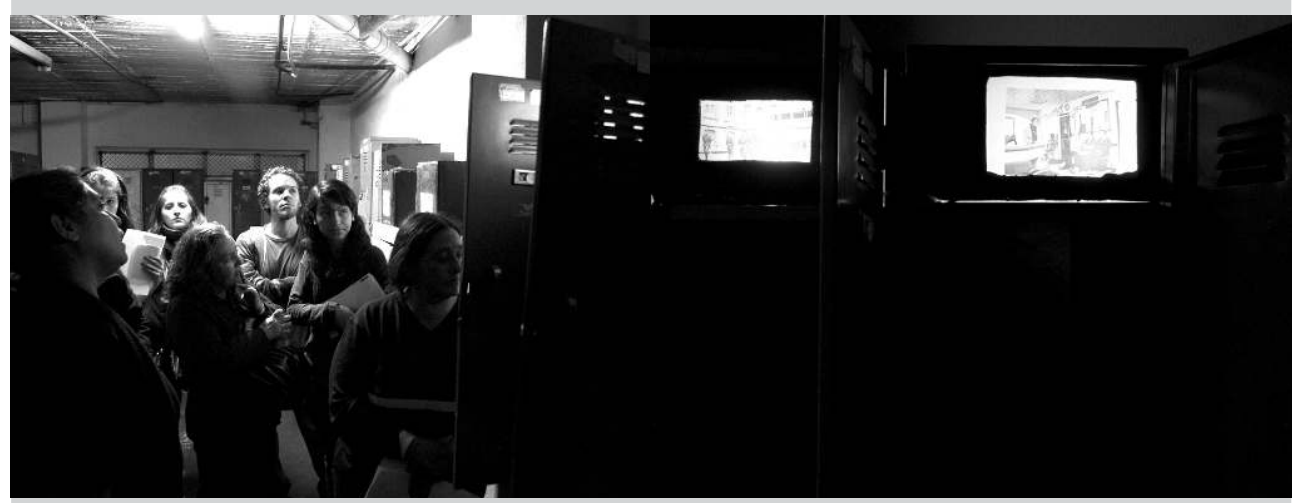

Figuras 28 y 29 - Casilleros IMI; imágenes proyectadas en cajas de luz y acetatos dentro de los casilleros IMI.

Fotografías: Colectivo IMIenEspera. 2011. Instalaciones, talleres y arte gráfico: IMIenEspera y La Carpa.

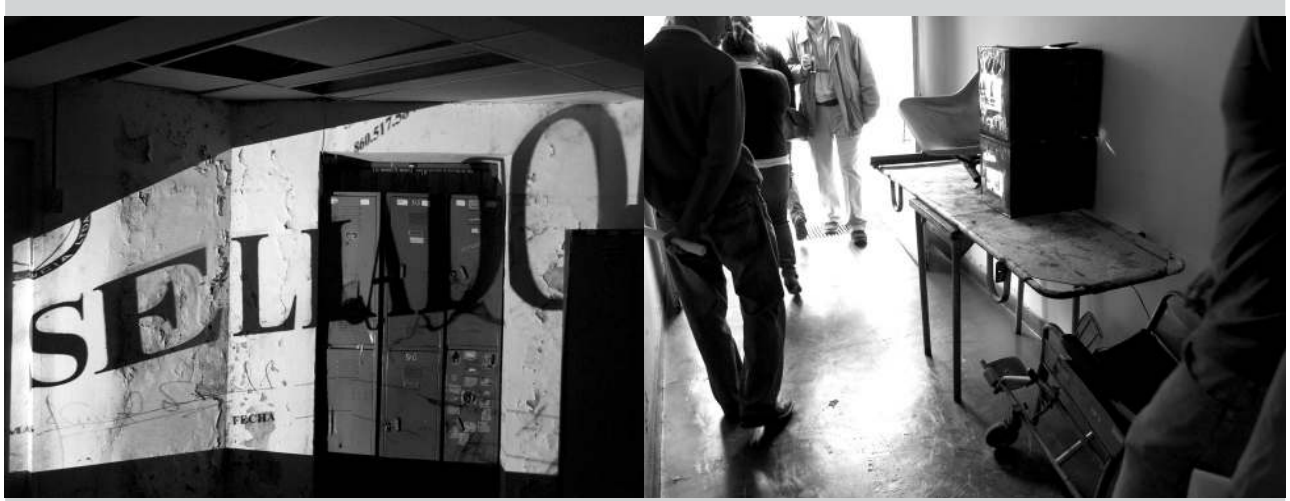

Figuras 30 y 31 - Proyecciones sobre casilleros en el IMI; instalación con cajas de luz y barricada IMI.

Fotografías: Colectivo IMIenEspera. 2011. Instalaciones, talleres y arte gráfico: IMIenEspera y La Carpa. 
los encuentros con la policía son varias e incluyen como eje común la conjunción de varios símbolos de violencia (de género, de mercado, de Estado) en el enfrentamiento entre mujeres de un hospital materno resistiendo la entrada de hombres acorazados, armados con bolillos, caucheras y gases lacrimógenos.

\section{Programa Madre Canguro (1978)}

Esta parada era clave para entender uno de los programas insignias del hospital que consistió en el reemplazo de uso de incubadoras en neonatos por el contacto piel a piel entre madres, padres u otros familiares y el recién nacido prematuro o de bajo peso, tal como lo hacen los marsupiales. La práctica surgió a raíz de la escasez de incubadoras y las necesidades crecientes de atención a familias pobres y sus recién nacidos. Los resultados fueron catalogados como "milagrosos", ya que los bebés canguro exhibían iguales tasas de supervivencia que los bebés que permanecían en incubadoras. El programa Madre Canguro fue reconocido por la Organización Mundial de la Salud y por UNICEF, y fue exportado exitosamente a todo el mundo.

\section{7. ¿Y el San Juan de Dios?}

Pare ese entonces, el fotógrafo Nicolás Van Hemelryck había desarrollado una serie de fotografías sobre el HSJD. Conversamos con él y decidimos que parte de la exposición podía mostrarse durante el recorrido, para así hacer énfasis en la conexión profunda entre las dos instituciones. ${ }^{7}$ En dichas fotos se pueden ver dramas similares a los del IMI, sin embargo, con distintas historias, porque el HSJD fue cerrado en 2000, no fue subarrendado y muchas familias decidieron vivir al interior del hospital.

\section{8. "Tomás" y El Cartucho...}

En un aula de clase del hospital las y los visitantes podían ver a "Tomás", un viejo esqueleto humano apodado así por los estudiantes, y usado como elemento pedagógico. En esta aula ubicamos unas sillas para proyectar dos materiales audiovisuales. El primero, llamado Bicentenario de la Salud en Colombia: Silenciando Patrimonios y Derechos, es dirigido por Jana Montllor; el segundo era un corto foto reportaje que contaba el testimonio de una vecina que había nacido en el IMI, crecido en el barrio el Cartucho, y quien para entonces estaba viviendo en un barrio cercano al IMI, el San Bernardo, después del desplazamiento masivo que sucedió cuando las autoridades de la ciudad demolieran el primero. En su relato ella cuenta su estrecha relación con el HSJD y el IMI, la calidad en la atención recibida, y de alguna manera narra como el hospital

7 En este link se puede observar una muestra de la exposición mencionada: < http://www.san-juan-d e-dios.com/index.php > (última consulta en Octubre de 2018). 
La Hortúa, como se conocía coloquialmente el complejo hospitalario, jugó un papel crucial en la vida de sus vecinos. ${ }^{8}$

Allí también Ingrid Morris, antropóloga, quien para entonces estaba a punto de publicar su libro En Un Lugar Llamado El Cartucho (Morris Rincón 2011), contextualizó el drama de miles de personas y familias desalojadas del barrio El Cartucho. El proceso sucedía en simultáneo con uno de renovación urbana del centro de la ciudad, caracterizado por el desplazamiento de personas y barrios pobres, y la promesa de "limpiar" el centro de personas no deseables ${ }^{9} \mathrm{y}$ remplazar su población con personas de "mejor nivel" que pudieran disfrutar, entre otros, de una red de hospitales modernizados y afines a las demandas del turismo internacional en salud, llamada pomposamente Ciudad Salud. ${ }^{10}$

\section{El muro de la discordia}

El 4 de junio de 2009 Camilo fue con su cámara, temprano en la mañana, citado por Marisol porque era necesario registrar la consolidación de la venta de parte del garaje del IMI al Instituto Nacional de Cancerología, entidad vecina del IMI que sí había logrado hacer una transición exitosa entre el modelo de salud anterior y el marco privatizador de la Ley 100. Dicha entidad había realizado la compra del garaje a la agencia liquidadora liderada entonces por la burócrata Ana Karenina Gauna. A través de las ventanas destartaladas del cuarto piso en la fachada sur del IMI, las personas que nos acompañaron en los recorridos podían ver el mencionado muro coronado por un alambre de púas y a la institución vecina detrás de este.

\section{Hospitalización}

Recorrimos los pisos 3 y 4 del hospital a través de sus corredores y cuartos vacíos, mientras las trabajadoras narraban historias sobre como transcurrían sus trabajos y vidas cotidianas en plena actividad del hospital. Compartían en detalle las dinámicas de interacción entre ellas, las pacientes, los estudiantes y los maestros, usualmente fraternales y caracterizadas por el apoyo y el respeto. La idea de la gran familia IMI emergía a cada instante, así como lo crucial del IMI en sus vidas como empleador, lugar donde muchas conocieron a sus parejas, donde nacieron sus hijos, y donde aprendieron a cuidar.

\section{Unidades de cuidados intensivos}

Recorrer las unidades de cuidados intensivos en el cuarto y último piso del IMI fue importante para entender la complejidad y la variedad de procedimientos

8 En el siguiente vinculo se puede ver el testimonio mencionado: < https://www.youtube.com/watch? $\mathrm{v}=\mathrm{zZarVvM9NA8}>$ (última consulta en Octubre de 2018).

9 Para esta discusión, ver Góngora y Suárez (2008).

10 Para profundizar en el proceso de gentrificación planeada del centro de Bogotá y su relación con el complejo HSJD-IMI, se puede leer el artículo de Marco Melo Moreno (2013). 


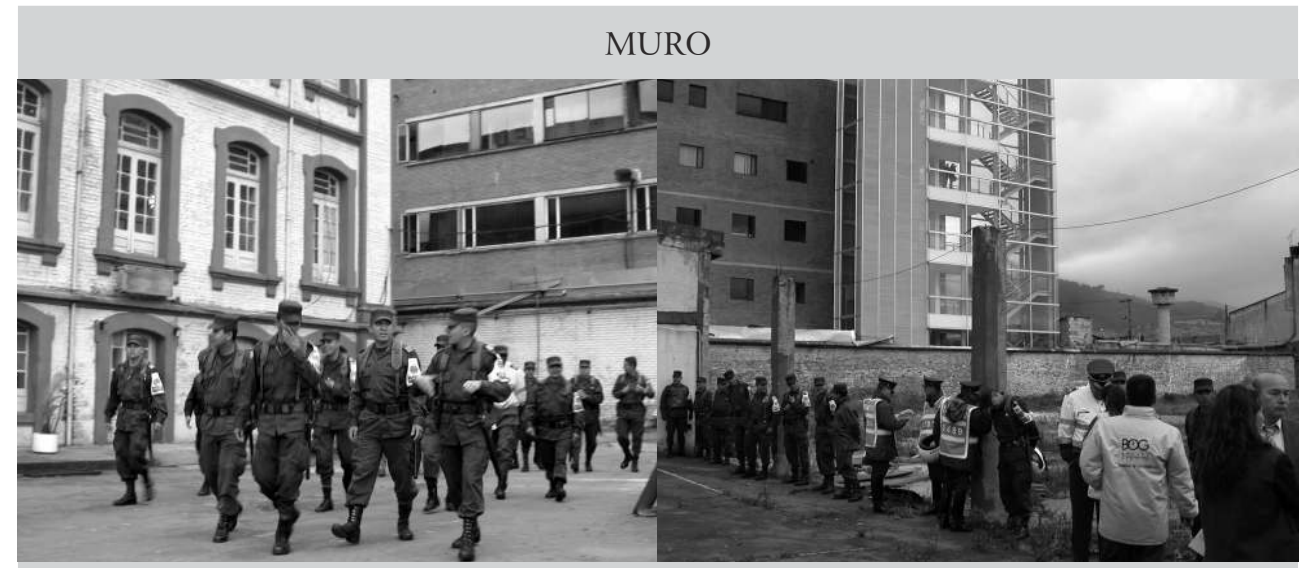

Figuras 32 y 33 - Entrada de la policía para proteger la venta de parte del parqueadero del IMI al ICC; la policía delinea el límite y futuro espacio para construir el muro divisorio. Fotografías: Héctor Camilo Ruiz Sánchez, 2009.

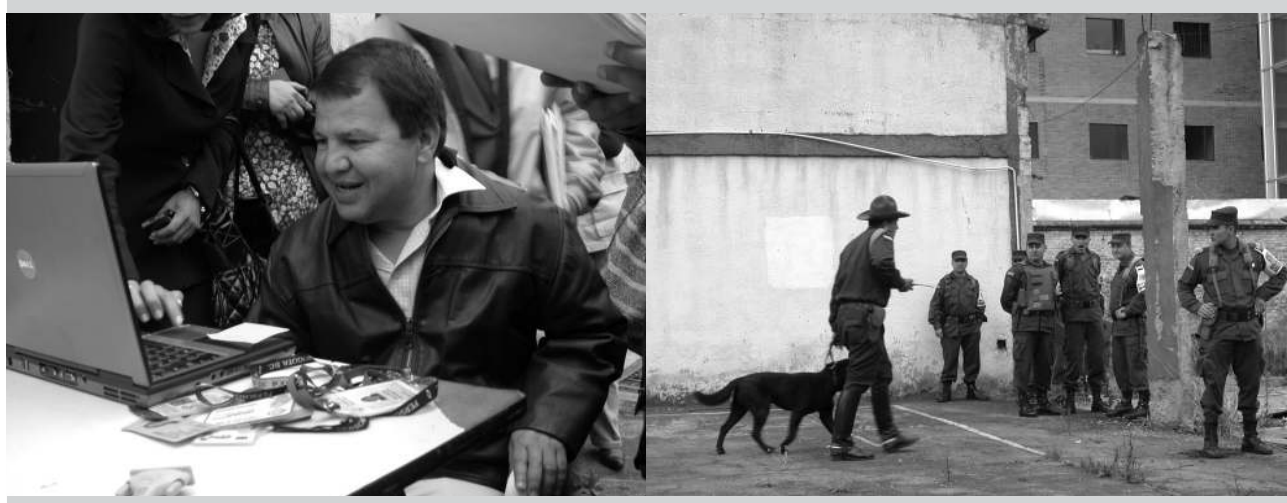

Figuras 34 y 35 - El acto burocrático in situ, que legitimó la venta del parqueadero; policía con perro anti explosivos, explorando el terreno por posibles amenazas al proceso de venta. Fotografías: Héctor Camilo Ruiz Sánchez, 2009.

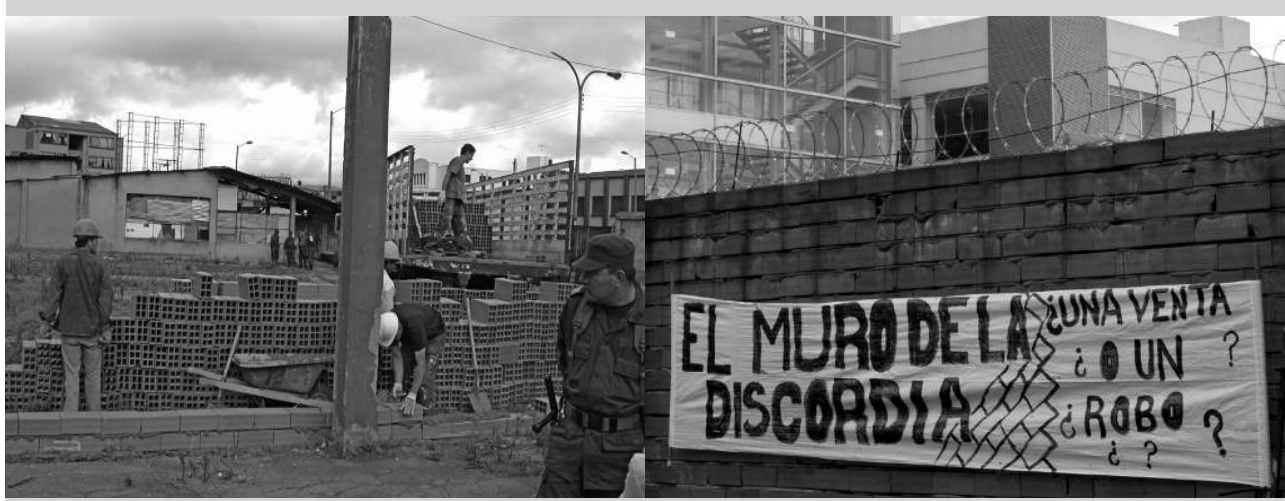

Figuras 36 y 37 - Construcción del muro; muro finalizado y grafiti/pancarta. Fotografías: Héctor Camilo Ruiz Sánchez, 2009.

Autor del arte gráfico: La Carpa. 


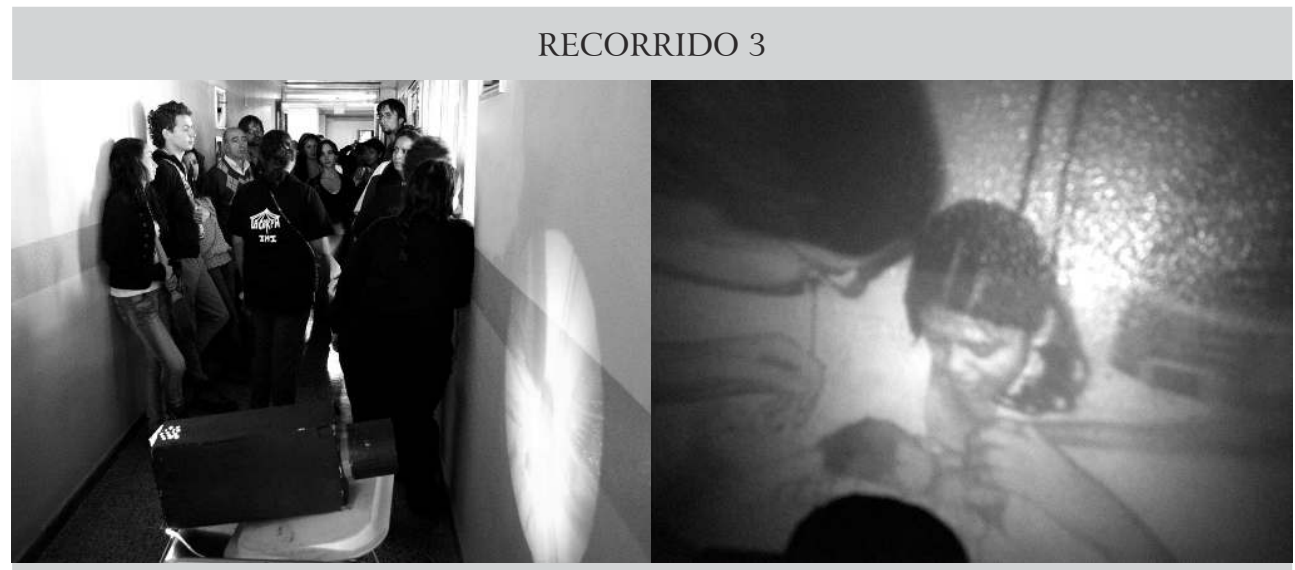

Figuras 38 y 39 - Pasillo IMI; proyección sobre pasillo IMI.

Fotografías: Colectivo IMIenEspera. 2011.

Instalaciones, talleres y arte gráfico: IMIenEspera y La Carpa.
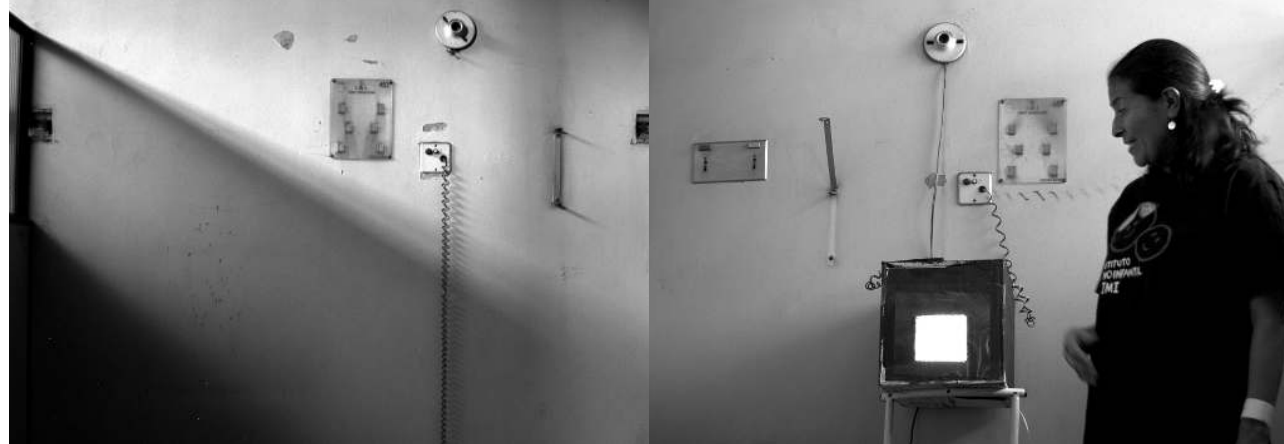

Figuras 40 y 41 - Habitación abandonada IMI; trabajadora IMI explicando su labor en el IMI a través de la imagen evocada en caja de luz.

Fotografías: Colectivo IMIenEspera. 2011. Instalaciones, talleres y arte gráfico: IMIenEspera y La Carpa.

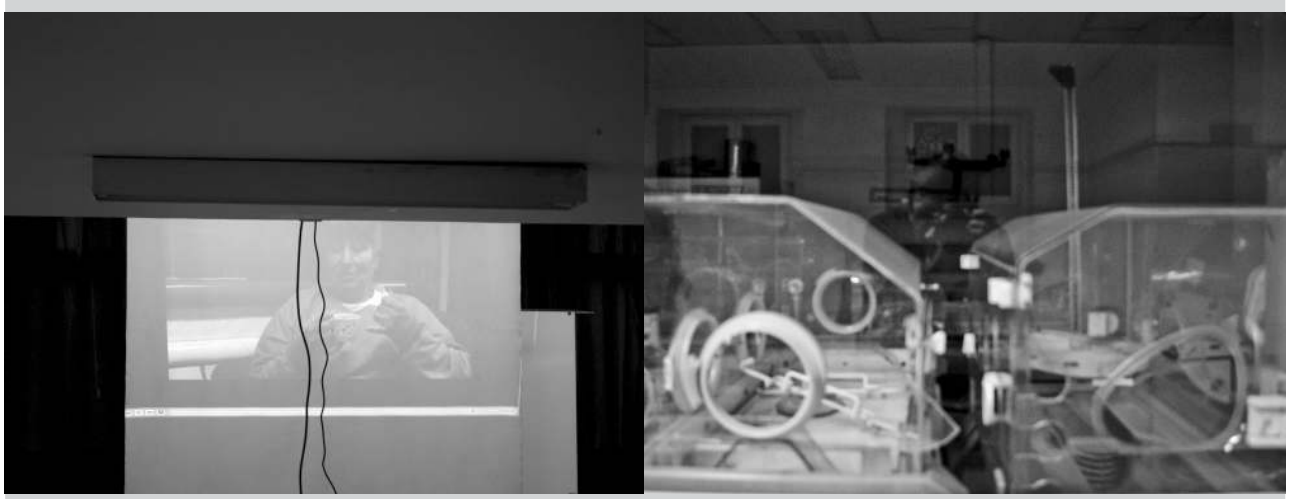

Figuras 42 y 43 - Fragmento de documental proyectado en aula del IMI; incubadoras abandonadas IMI.

Fotografías: Colectivo IMIenEspera. 2011. Instalaciones, talleres y arte gráfico: IMIenEspera y La Carpa. 
que allí se realizaban. Los relatos sobre las prácticas, los trabajos, los pacientes, y la investigación contrastaba con las imágenes de salas vacías con sus ventanas y techos rotos, pilas de colchones enmohecidos, y rastros de camas y equipos ausentes. También recorrimos salas selladas repletas de incubadoras abandonadas, empolvadas y vacías.

A los tres recorridos asistieron en promedio 15 personas, hecho que habla de lo difícil que fue convocar un público amplio. Además, todos los recorridos requirieron de un gran esfuerzo para el montaje ya que nadie podía cuidar de los objetos en nuestra ausencia, así que al final de cada uno de los tres sábados tuvimos que desmontar todos los objetos, así como devolver y volver a pedir prestados proyectores, computadores, reproductores de audio y parlantes. Todos los montajes se hicieron con mano de obra donada por miembros de La Carpa, del Grupo de Antropología Médica Crítica de la Universidad Nacional y del colectivo IMIenEspera.

En suma, si bien habíamos logrado crear tres visitas guiadas con muy pocos elementos, mucha creatividad y bastante trabajo, éstas nos dejaron un sabor agridulce. Para el 2011 las trabajadoras habían sido abordadas demasiadas veces por periodistas, fotógrafos, estudiantes, investigadores y políticos, que querían sus historias, palabras, y vidas, para ser transmitidas en un noticiero, escritas en un ensayo, impresas en unas fotografías o utilizadas como promesas electorales. Y aunque estas visitas eran vistas como oportunidades políticas para contar lo que estaba sucediendo y, tal vez, ganar ideas y apoyo para gestar nuevas estrategias de lucha, en muchas ocasiones el resultado era una versión tergiversada de sus vidas y luchas, dejando una sensación de indignación frente a lo que se consideraba como un engaño.

Así, el esfuerzo y carga emotiva de contar y recontar la historia parecía no compensarse con los resultados, y concluimos que las visitas guiadas no habían logrado escapar de esta dinámica frustrante. Sin embargo, quedaron muchos recuerdos divertidos y anécdotas de los momentos antes y después de los recorridos y una sensación de gratificación y reconocimiento de la importancia política de la lucha que adelantaban por sus derechos laborales y por el derecho a la salud en Colombia - en últimas, la importancia de reafirmar y ser reafirmados, de reconocer y ser reconocidos.

\section{DISCUSIÓN: LA ECONOMÍA POLÍTICA DEL ARTE, AFECTO Y ACOMPANAMIENTO}

"las prácticas artísticas tienen un rol fundamental, al generar espacios reflexivos y críticos que permitan abordar desde diferentes costados la coyuntura presente, al cuestionar lugares comunes y proponer nuevas formas de ver, oír y sentir, a través de sus diferentes propuestas políticas, estéticas y éticas del tiempo y de las miradas" (Cortés Severino 2009: 169). 
El rol del arte en esta investigación colaborativa y comprometida (Fluehr-Lobban 2008; Hall 2006) ha sido fundamental para entender cómo se relaciona la lucha de las trabajadoras del hospital con las fuerzas del neoliberalismo en la salud en Colombia. En efecto, más que una propuesta metodológica, la ética de la etnografía volcada a la acción (Bourgois 1990; Fluehr-Lobban 2008; Hall 2006) abre nuevas posibilidades conceptuales e interpretativas para el trabajo antropológico (Holmes y Marcus 2008).

Fotografías, grafitis, instalaciones, proyecciones, junto con las voces de las trabajadoras, se convirtieron en vehículos para expresar, evocar y transmitir emociones, como dignidad, respeto o ira. A la vez, estas propuestas nos permitieron profundizar nuestras interpretaciones académicas y posicionar mejor las acciones políticas; logramos entender la historia reciente del IMI de otra manera, desde el arte, que es el que nos permite de cierta manera divulgar en este texto la historia de lucha de las trabajadoras del IMI, y así replicar nuestro objetivo inicial, que es contar esta historia a un público más amplio.

El IMI, más allá de ser un edificio, es también una entidad viva, con historia, agencia y un futuro incierto. Los grafitis y textos que se han plasmado sobre sus superficies, al igual que los estragos propios del abandono, metafóricamente se pueden leer como tatuajes sobre el mismo cuerpo del hospital, y como tal, también se pueden leer y agrupar a modo de archivo. Tradicionalmente los archivos se han usado y leído como colecciones, producto de explotaciones coloniales. A diferencia de este abordaje, queremos leer el archivo gráfico del IMI bajo la propuesta de la antropóloga Ann Stoler (2002), que consiste en dar tres giros conceptuales para ver e interpretar los archivos de manera diferente. Primero, hay que verlos como procesos y no como cosas; segundo, entenderlos como experimentos epistemológicos en vez que como solo fuentes; y tercero, asumirlos como intersecciones donde el conocimiento es también cuestionado y re-inventado. Así, el archivo gráfico del IMI lo leemos y lo proponemos como un proceso en constante transformación, como una alternativa y medio de protesta, y como un ejercicio de memoria alternativo. Este se convierte y lo entendemos como un archivo de carácter político por el cual, a la Spivak (2010), el subalterno se expresa.

Respecto a los recorridos guiados, lo que intentamos con estos fue adentrarnos en el hospital para que este contara su historia de lucha y resistencia a través de audios, instalaciones, anécdotas y videos. También queríamos exponer su decadencia a un nuevo público, manifestada en su profundo vacío, sus paredes húmedas, el óxido de instrumentos médicos, y el casi extinto olor a leche materna que lo caracterizaba. La propuesta era crear una visita emotiva, que lograra transmitir la tragedia del hospital y sus trabajadoras como una unidad política de gran trascendencia para la historia del país. En este sentido, el arte abre otras posibilidades emocionales, analíticas y de justicia social para las propuestas enmarcadas en la etnografía pública (Degarrod 2013). 
Pink (2012) propone, y nosotros concordamos con ella, que la vida cotidiana y el activismo están localizados y son al mismo tiempo (1) materia dinámica y en constante cambio, (2) ambientes sociales y sensoriales, y (3) maneras cambiantes de percibir, sentir y saber. Bajo esta perspectiva, los recorridos surgieron como un proyecto que buscaba no solamente generar una experiencia emotiva en los visitantes, sino también transformar temporalmente el espacio del IMI a través de la construcción de una atmosfera de solidaridad, diálogo y aprendizaje y, a su vez, hacer un llamado enfático a la acción de defensa de la institución y sus trabajadoras.

De esta manera, los recorridos en el IMI hechos por el colectivo temporal IMIenEspera surgen como otra manera más de hacer algo por el hospital y sus trabajadoras. Estos tenían como objetivo impactar a los visitantes con una experiencia emocional que transmitiera las complejidades de lo que allí sucedía, la importancia del hospital para el país, y además contar la historia desde el mismo IMI sin las tergiversaciones propias de los noticieros, periódicos e investigadores, que tantas veces habían cooptado su historia.

Las intervenciones artísticas que creamos en el IMI tomaron diferentes formas, creando mensajes sobre el valor patrimonial del hospital, la lucha política de las trabajadoras por sus derechos al trabajo y a una indemnización laboral justa. Creemos que con nuestra participación y aprendiendo de ellas, apoyamos a La Carpa en su esfuerzo por expandir su mensaje en otros tiempos y espacios, como con el público de las visitas guiadas, quienes escucharon su historia en espacios académicos, o quienes leen este texto.

Así el rol de la academia no se limitó a registrar, abogar, o producir documentos para una comunidad académica idealizada. En nuestra propuesta de etnografía colaborativa liderada por propuestas artísticas, nosotros trajimos nuestros capitales (sociales y culturales) al proceso político, y haciendo esto, los límites entre el grupo de trabajadoras y nuestra propuesta académico-activista se volvieron más porosos. Las trabajadoras participaron en eventos académicos que organizamos, y nosotros participamos en la intervención del hospital. Ellas nos ayudaron a entender el proceso político y legal por el que estaban pasando, para luego traducirlo en un lenguaje académico, y nosotros les ayudamos a entender y documentar aspectos del proceso que les han ayudado en su lucha.

Y es que el arte y la antropología muchas veces son encuentros que producen formas y apropiaciones híbridas que abren espacios para la discusión, la reflexión y la interpretación; situaciones no siempre cómodas, ni claras, y muchas de las veces tensas y en constante cambio (Cox, Irving y Wright 2016). Nuestro ejercicio de arte y activismo en el IMI refleja la incomodidad del fracaso frente a los objetivos políticos no logrados, pero al mismo tiempo encuentra satisfacción al encontrar nuevas maneras de entender y sentir al IMI y el drama de sus trabajadoras a través de los ejercicios y actividades realizadas. 
Los recorridos por sus grafitis e instalaciones junto a las intervenciones artísticas, e incluso este texto, son experimentos que abogaron por nuevas formas de acercarse a ese "otro" antropológico, y escribir y exhibir el trabajo etnográfico de maneras diferentes. Le apuntamos a metodologías de recolección y evocación que fueron más allá de las clásicas entrevistas y etnografías para intentar registrar y transmitir emociones políticas a través de narrativas escritas, audiovisuales y sensoriales, con el objetivo de llegar a públicos más amplios y con un material cargado de mayor contundencia política, reflexiva y emocional (Degarrod 2013; Fluehr-Lobban 2008; Holmes y Marcus 2008). Así, lo que logramos fue crear una nueva experiencia en el y del trabajo de campo, cuyos resultados fueron indeterminados, pero del cual surgieron nuevas formas de entender la existencia del IMI, tal vez más alejadas de la, a veces, abstracta teoría, y más cercanas al hospital, sus trabajadoras y nosotros mismos.

Aquí es importante aclarar que estas intervenciones artístico-políticas crearon un desgaste emocional en todos los participantes. Muchas memorias y sensaciones de dolor y frustración fueron evocadas y revividas. Por lo tanto, una evaluación sobre lo benéfico o perjudicial de estos ejercicios no es estática, varía según el momento de la evaluación y la energía particular que el grupo maneje en su momento. Depende también de resultados concretos y de noticias y novedades sobre sus asuntos legales y sobre el futuro del hospital.

Para concluir, consideramos que este proceso nos ha enseñado que no siempre es claro cuáles son los efectos ni qué tanto ayudan actividades ligadas al activismo y el arte en procesos de investigación académica. Sin embargo, cuando esa ansiedad, desesperación, y sobretodo frustración se apoderan de uno, la practicidad política de la líder de La Carpa, Marisol, emerge elocuentemente como una señal de esperanza, recordándonos que al igual que ellas lo han hecho, la única opción que existe para quienes nos empeñamos en insistir en la lucha política es la de seguir intentando. 


\section{BIBLIOGRAFÍA}

ABADÍA-BARRERO, César E., 2015, “The transformation of the value of life: dispossession as torture", Medical Anthropology, 34 (5): 389-406.

ABADÍA BARRERO, César, et al., 2011 , "Algunas violencias del capitalismo en Colombia: dispositivos de tortura y autodestrucción”, Maguaré, 25 (1): 203-240.

BOCHETTI, Carla, Juan Manuel ARTEAGA, y Marco PALACIOS, 2005, Hospital Universitario: Desde San Juan de Dios Hasta la Construcción de Un Nuevo Proyecto. Bogotá, Universidad Nacional de Colombia.

BOURGOIS, Philippe, 1990, "Éticas antropológicas en confrontación: lecciones etnográficas de Centro América”, Estudios Sociales Centroamericanos, 54: 101-117.

CORTÉS SEVERINO, Catalina, 2009, "Recolecciones sonoras y visuales de los escenarios de memorias de la violencia”, Antípoda, 9: 165-197.

COX, Rupert, Andrew IRVING, y Christopher WRIGHT, 2016, Beyond Text? Critical Practices and Sensory Anthropology. Manchester, Manchester University Press.

DEGARROD, Lydia N., 2013, "Making the unfamiliar personal: arts-based ethnographies as public-engaged ethnographies”, Qualitative Research, 13 (4): 402-413.

FLUEHR-LOBBAN, Carolyn, 2008, "Collaborative anthropology as twenty-first-century ethical anthropology", Collaborative Anthropologies, 1 (1): 175-182.

FOUCAUlT, Michel, 1984, "What is an author?", en Paul Rabinow (comp.), The Foucault Reader. Nueva York, Pantheon Books, 101-120.

GÓNGORA, Andrés, y Carlos José SUÁREZ, 2008, "Por una Bogotá sin mugre: violencia, vida y muerte en la cloaca urbana”, Universitas Humanística, 66: 107-138.

GÓNGORA, Andrés, et al., 2013, "El San Juan Muere de Pie": La Vida Social de un Hospital y la Construcción de Una Causa (Informe de Investigación). Bogotá, Facultad de Medicina de la Universidad Nacional de Colombia.

HALL, Charles R., 2006, "Activist research v. cultural critique: indigenous land rights and the contradictions of politically engaged anthropology", Cultural Anthropology, 21: 96-120.

HERNÁNDEZ ALVAREZ, Mario, y Diana OBREGÓN TORRES (comps.), 2002, La Organización Panamericana de la Salud y el Estado Colombiano: Cien Años de Historia, 1902-2002. Bogotá, Organización Panamericana de la Salud.

HOLMES, Douglas R., y George E. MARCUS, 2008, "Collaboration today and the re-imagination of the classic scene of fieldwork encounter", Collaborative Anthropologies, 1 (1): 81-101.

MELO MORENO, Marco A., 2013, “'Quítate tú pa’ ponerme yo’: un análisis prospectivo de Ciudad Salud desde una perspectiva marxiana”, en C. E. Abadía Barrero et al. (comps.), Salud, Normalización y Capitalismo en Colombia. Bogotá, CES Universidad Nacional/Ediciones Desde Abajo/Ediciones Universidad del Rosario, 413-440.

MORRIS RINCÓN, Ingrid, 201 1, En Un Lugar Llamado El Cartucho. Bogotá, Alcaldía Mayor de Bogotá, Instituto Distrital de Patrimonio Cultural.

OLIVEIRA, Roberto Cardoso de, 2004, "O mal-estar da ética na antropologia prática”, en Ceres Víctora et al. (comps.), Antropología e Ética: O Debate Atual no Brasil. Niteroi, Editora da Universidade Federal Fluminense, 21-32.

PINK, Sarah, 2012, Situating Everyday Life: Practices and Places. Los Angeles, Sage.

RESTREPO ZEA, Estela, 2011, El Hospital San Juan de Dios 1635-1895: Una Historia de la Enfermedad, Pobreza y Muerte en Bogotá. Bogotá, Centro de Estudios Sociales, Universidad Nacional de Colombia. 
SILVA TÉlleZ, Armando, 1998, Álbum de Familia: La Imagen de Nosotros Mismos. Bogotá, Grupo Editorial Norma.

SILVA TÉlleZ, Armando, 2013, Atmósferas Ciudadanas: Grafiti, Arte Público, Nichos Estéticos. Bogotá, Universidad Externado de Colombia.

SPIVAK, Gayatri Chakravorty, 2010, "Can the subaltern speak?", en Rosalind C. Morris (comp.), Can the Subaltern Speak? Reflections on the History of an Idea. Nueva York, Columbia University Press, 21-78.

STOLER, Ann, 2002, "Colonial archives and the art of governance", Archival Science, 2: 87-109.

YEPES, Francisco J., et al., 2010, Luces y Sombras de la Reforma de la Salud en Colombia: Ley 100 de 1993. Bogotá, Assalud/Universidad del Rosario, Facultad de Economía/Mayolo Ediciones. 